NBER WORKING PAPER SERIES

\title{
MEASURING THE RETURNS TO R\&D: THE DEPRECIATION PROBLEM
}

\author{
Bronwyn H. Hall \\ Working Paper 13473 \\ http://www.nber.org/papers/w13473
NATIONAL BUREAU OF ECONOMIC RESEARCH
1050 Massachusetts Avenue
Cambridge, MA 02138
October 2007

This is a revision of a paper presented at the International Conference in memory of Zvi Griliches, Paris, August 2003 and the Conference in memory of Tor Jakob Klette, Oslo, Norway, in August 2004. The paper has benefited from comments by participants in those conferences and especially from comments by three referees and the editors of this special issue. The current version contains typesetting corrections as of July 2009. The views expressed herein are those of the author(s) and do not necessarily reflect the views of the National Bureau of Economic Research.

(C) 2007 by Bronwyn H. Hall. All rights reserved. Short sections of text, not to exceed two paragraphs, may be quoted without explicit permission provided that full credit, including $\odot$ notice, is given to the source. 
Measuring the Returns to R\&D: The Depreciation Problem

Bronwyn H. Hall

NBER Working Paper No. 13473

October 2007, Revised July 2009

JEL No. D24,G12,L20,O30

\begin{abstract}
Measuring the private returns to $R \& D$ requires knowledge of its private depreciation or obsolescence rate, which is inherently variable and responds to competitive pressure. Nevertheless, most of the previous literature has used a constant depreciation rate to construct R\&D capital stocks and measure the returns to $R \& D$, a rate usually equal to 15 per cent. In this paper I review the implications of this assumption for the measurement of returns using two different methodologies: one based on the production function and another that uses firm market value to infer returns. Under the assumption that firms choose their R\&D investment optimally, that is, marginal expected benefit equals marginal cost, I show that both estimates of returns can be inverted to derive an implied depreciation rate for R\&D capital. I then test these ideas on a large unbalanced panel of U.S. manufacturing firms for the years 1974 to 2003. The two methods do not agree, in that the production function approach suggests depreciation rates near zero (or even appreciation) whereas the market value approach implies depreciation rates ranging from 20 to 40 per cent, depending on the period. The concluding section discusses the possible reasons for this funding.
\end{abstract}

Bronwyn H. Hall

Dept. of Economics

549 Evans Hall

UC Berkeley

Berkeley, CA 94720-3880

and NBER

bhhall@nber.org 


\title{
Measuring the Returns to R\&D: The Depreciation Problem
}

\author{
Bronwyn H. Hall
}

\section{Introduction}

Throughout his long career, the measurement of the returns to $R \& D$ investments was a central concern of Zvi Griliches' research endeavor. His first paper on this topic was published in the Journal of Political Economy in 1958 and his last thoughts on it are contained in the small volume based on his Kuznets lectures and entitled $R \& D$, Education, and Productivity that was published posthumously in 2000 by Harvard University Press. Between these two poles lie a number of works that pushed the analysis forward but at the same time identified a series of issues that had to be dealt with in order to be confident in the measures being estimated. This article reviews and summarizes these issues and highlights the problem of reconciling measures obtained using differing methodologies that was raised by Griliches in his earlier 1996 article, "R\&D and Productivity: The Unfinished Business". ${ }^{2}$ It then goes on to argue that the measurement of the depreciation of R\&D assets is the central unsolved problem in the measurement of the returns to $\mathrm{R} \& \mathrm{D}$, and illustrates the difficulties raised by depreciation using updated estimates of the private returns to R\&D in U.S. manufacturing firms during the past 30 years.

The first Griliches paper (JPE 1958) on measuring the social returns to the research that lay behind the development of hybrid corn was drawn from his thesis research. Looking back on this paper today, two things strike one: first, the effort he devoted to ensuring that the rate measured was the social rate (incorporated all of the supply and demand response) and second, the clear understanding and discussion of the problem of ex ante and ex post returns and the importance of timing in measuring the rate of return. This paper was followed in 1967 by the well-known work with Jorgenson that sought explanations for the productivity residual via improvements in measurement of the inputs. In Griliches' case, this particular exploration, which relied heavily on the quality improvement of the inputs to production, lead to interest in measuring the returns to

${ }^{2}$ A revised version of Griliches (1996) appeared as Chapter 4 of Griliches (2000). 
human capital formation in the early 1970s (Gronau, this issue), and renewed attention to the problem of measuring the returns to $\mathrm{R} \& \mathrm{D}$, this time outside the agricultural sector, in the late 1970s. The latter endeavor was partly inspired by the productivity slowdown during the 1970s following the first oil price shock in 1973-1974. In 1978, Griliches undertook a large project at the NBER funded by the National Science Foundation and joint with M. I. Nadiri and various junior researchers that aimed to study a number of questions related to the productivity of R\&D. This project created and used a new dataset of publicly traded U.S. manufacturing firms that had been matched to their patent portfolios. The data used in the present paper is an extension and outgrowth of that project. ${ }^{3}$ The results of much of the research done by participants in the project are contained in the 1984 conference volume edited by Griliches.

The 1979 article in the Bell Journal laid the groundwork for the research conducted during this project and also raised a number of issues that have informed much of subsequent work by Griliches himself, his students, and other researchers. He returned to these questions towards the end of his life in three articles: the AEA Presidential address of 1994, the 1996 article already mentioned, and the Kuznets lectures (2000). In this paper I make some modest progress in answering some of the questions raised in these articles: first, can we reconcile the R\&D returns estimates from the productivity and market value equations? Second, what is the explanation for the changes in the marginal productivity of R\&D over time identified by Hall (1993) and Hall and Kim (1999)? Third, can we use the fact that the returns or productivity results vary across broad industrial sectors to inform us on the first two questions? In attempting to answer these questions, my focus is on the role of $\mathrm{R} \& \mathrm{D}$ depreciation or obsolescence at the firm level and its effects on the measurement of the returns to R\&D. Estimating the private returns to R\&D using either a revenue production function (flow method) or market value equation (present discounted value of future flows method) confronts the same problem: computing the net rate of return or interpreting the shadow value of the R\&D stock requires an assumption about the private depreciation or obsolescence of the asset generated by the R\&D investments.

\footnotetext{
${ }^{3}$ Although the panel data set used here is similar to that in Hall, Jaffe, and Trajtenberg (2005), it is in fact a more recent sample drawn from Standard and Poors' Annual Industrial Compustat files, and it therefore does not contain the patent data (yet).
} 
However, determining the appropriate depreciation rate is difficult if not impossible, for at least two reasons. First, from the firm's perspective, the appropriate depreciation rate is endogenous to its behavior and that of its competitors, in addition to depending to some extent on the progress of public research and science. Therefore there is no reason to assume that it is constant over time or over firm, although it will usually (but not always) change slowly in the time dimension. Second, identifying the depreciation rate independently from the return to $R \& D$ requires determination of the lag structure of $R \& D$ in generating returns. But years of experience with the specification of production functions, market value equations, or even patent production functions (Hall, Griliches, and Hausman 1989) has shown convincingly that this is extremely difficult, because of the lack of appropriate natural experiments. That is, in practice R\&D does not vary much over time within firm, so that trying to identify more than one coefficient of R\&D is problematic and leads to very unstable results. In the data used in this paper, which is a fairly heterogeneous time series-cross section of firms, the variance of $\mathrm{R} \& \mathrm{D}$ growth rates within firms is only about 4 per cent of the variance of the levels. In addition, as has been observed by earlier authors (e.g., Hall and Mairesse 2005), the log R\&D series exhibits close to random walk behavior. ${ }^{4}$ The implication of these properties is that including more than one linear function of the $(\log ) \mathrm{R} \& \mathrm{D}$ series in an equation will be a futile exercise.

Given the problem of estimating R\&D depreciation by including a distributed lag in either the production function or market value equation, in this paper I turn the problem on its head and try to infer the private $R \& D$ depreciation rate from the measured returns to $R \& D$ by assuming that the net return is determined by the financial markets and therefore roughly equal across comparable firms in equilibrium. Thus the paper offers an interpretation of the widely varying market value and productivity of $R \& D$ at the firm level over time, one that is based on the idea of continuous creative destruction of the rents created by R\&D investments. I find that the two different approaches to estimating $R \& D$ returns do not agree, in that the production function approach suggests depreciation rates near zero (or even appreciation) whereas the market value

\footnotetext{
${ }^{4}$ The correlogram for the first three lags of the data used here is $(0.99,0.97 .0 .96)$ and the partial correlogram is $(0.99,0.00,0.00)$
} 
approach implies depreciation rates ranging from 20 to 40 per cent, depending on the period. The concluding section of the paper discusses the possible explanations for these findings.

The paper begins with a brief discussion of the data and the basic facts on R\&D, productivity, and market value that it contains. The dataset is a comprehensive unbalanced panel of publicly traded U.S. manufacturing firms observed from 1974 to 2003, a thirty year period. The next section of the paper presents the familiar framework for the estimation of the returns to R\&D using the production function, discusses the interpretation of the results and presents some estimates, for the manufacturing sector as a whole and for six subsectors, grouped by technology. This is followed by a presentation of the alternative methodology for measuring R\&D returns, the market value approach pioneered by Griliches. Empirical results from estimating the market value equation with $R \& D$ capital are then presented and the implied depreciation of $R \& D$ is computed. Conclusions follow.

\section{Data}

The starting point for the panel used in this paper was the population of U.S. manufacturing firms on the Compustat files between 1970 and 2004. Cleaning the data and removing foreign firms, subsidiaries, and those that did not engage in $R \& D$ at least some of the time resulted in a panel with 28,937 observations for the 1974-2003 period. Appendix A gives the details of the sample construction.

Considerable experimentation with year-to-year estimates from this unbalanced panel revealed some instability in the coefficients due to fluctuations in variables and samples (see Figures 1 and 2 for some examples). Accordingly, it seemed preferable to focus the estimates in the tables on a series of panels balanced over 5-year periods rather than presenting possibly unstable yearly estimates. However, this decision comes at the cost of reducing the sample even further. The periods chosen were 1974-1978, 1979-1983, 1984-1988, 1989-1993, 1994-1998, and 1999-2003; an additional year of data prior to the period was also required in order to ensure that beginning of year capitals could be used where necessary. Table A1 in the appendix gives some information on the number of observations in the population and in the sample. The appendix also shows that although the balanced panel observations comprise only about a quarter of the 
original population, they cover more than three quarters of the R\&D in the publicly traded manufacturing sector. The unbalanced panel of 28,937 observations also includes about 90 per cent of the R\&D that was covered by the starting population of publicly-traded firms.

Most of the estimates in the paper have been computed using a least absolute deviations estimator rather than ordinary least squares, to reduce the sensitivity to outliers. Using LAD comes at the cost of neglecting biases that may be introduced by permanent unobserved differences across the firms that are related to their choice of inputs. The justification for this procedure is twofold: first, in the case of the market value equations, it is nearly impossible to find appropriate instruments after differencing to remove firm effects, and it is not even clear that it is desirable to remove these effects when estimating the market valuation of R\&D strategies. Second, in the case of production functions, the best estimator (GMM-system) tends to yield results that are similar to the estimates in levels (Blundell and Bond 1998). Finally, given the focus of the current paper on the macro-economic properties of R\&D investment over time rather than on causal models, it is inappropriate to condition on the individual firm effects as that omits the contribution from changes in their distribution.

Table 1 gives basic statistics on the two samples used for estimation, unbalanced and partially balanced. The median firm in both panels is large, with that from the balanced panel somewhat larger than from the unbalanced panel: 178 versus 300 million (1996) dollars of revenue, 1500 (2500) employees, ordinary capital stock of 77 (133) million dollars, and R\&D capital of 24 (37) million dollars. ${ }^{5}$ The median R\&D-sales ratio is 2.8 per cent, with a range from 0.1 per cent to 100 per cent (due to the cutoffs used in trimming the data). Tobin's q is highly variable and averages substantially higher than unity, even when it is corrected for the fact that R\&D capital has been left out of the denominator.

\section{[Table 1 about here]}

\footnotetext{
${ }^{5} \mathrm{R} \& \mathrm{D}$ capital is measured as described in equation (3) of the next section of the paper, using a depreciation rate of 15 per cent.
} 
Figures 1 and 2 report the time series trends in a number of key variables and estimates, computed using models described in more detail later in the paper. Figure 1 shows evolution of four series over the thirty-year period from 1974 to 2003: the R\&D capital stock-output ratio of the median firm, the marginal shadow value of R\&D capital estimated using a hedonic market value equation, the productivity of $\mathrm{R} \& \mathrm{D}$ capital estimated using a Cobb-Douglas production function, and the same productivity adjusted for double-counting of R\&D spending. ${ }^{6}$ The $R \& D$ capital intensity and the two R\&D productivity measures rise in parallel during the entire period, from $0.1,0.0$, and 0.05 respectively to $0.25,0.15$, and 0.2 . This is what one might have expected if the cost of $R \& D$ capital were roughly constant, $R \& D$ capital was measured correctly, and R\&D investment was in equilibrium. It implies a trend during the period of continuously increasing elasticity of output with respect to $R \& D$ investment. On the other hand, the market value of R\&D capital shows much larger swings, from about 0.5 in the mid-1970s to 1.2 , then falling again during the 1980s, and finally rising to well above one during the late 1990s.

\section{[Figures 1 and 2 about here]}

Figure 2 shows the same four series, but this time relative to ordinary capital. The advantage of such a formulation is that it abstracts from variations in the production or value function due to 1) differences in the share of purchased inputs that are not controlled for by the sector dummies, 2) scale economies or diseconomies, 3) imperfect competition effects that are consistent with a constant elasticity of demand function, and 4) macroeconomic effects in capital valuation. In this figure, the R\&D capital-tangible capital ratio rises smoothly from 0.2 to 0.4 and then falls again to 0.3 , whereas the relative productivity rises somewhat more steeply from around zero $(0.05$ if adjusted for double counting) to $0.4(0.5)$. Thus relative productivity increases faster than the capital stock ratio, which implies that the cost of $R \& D$ capital has risen relative to the cost of ordinary capital. The relative market value of $R \& D$ capital exhibits a similar pattern as the absolute market value, except that the earlier period is somewhat higher relative to the later, a result that is consistent with the fact that $R \& D$ investment in the 1974-1990 period increased in spite of its relatively low productivity. That is, the financial markets signaled during the 1970s

\footnotetext{
${ }^{6}$ This correction is discussed in section 3 of the paper.
} 
and 1980s that higher future returns to $R \& D$ were expected. Note, however, that the relative shadow value of R\&D capital is almost everywhere less than unity, which suggests either that it is mismeasured or that adjustment costs are higher for R\&D (so that increases towards an equilibrium level cannot be achieved as quickly).

Broadly speaking, these data reveal that the conundrum identified by Griliches is still there, but in a somewhat altered form. The relative elasticity of $R \& D$ has risen to the point where it is approximately equal to its relative share in production (under the assumption that the costs of capital do not differ too much), but the market value of R\&D is just as high as it was in the 19771983 period, when its productivity was much lower. There are a number of possible explanations for these findings and in the following two sections of the paper, I explore one of them: whether changing depreciation (increased obsolescence) of R\&D may help to explain why higher productivity has not lead to a much higher market value. In support of this investigation, I also present results for six major subsectors (chemicals, rubber, and plastics; pharmaceuticals and medical instruments; electrical machinery; computers and scientific instruments; metals, machinery, and transport equipment; and miscellaneous manufacturing), where we might suspect differing $R \& D$ obsolescence to be at work.

\section{Productivity}

The framework used by Griliches (and a host of subsequent researchers) to estimate the productivity of $R \& D$ or the private returns to $R \& D$ relies on the usual Cobb-Douglas production function augmented to include an additional input that he called "knowledge" capital. A survey of results obtained using this model is given by Mairesse and Mohnen (1990) and the econometric issues that arise in estimating production functions in general have been reviewed in Griliches and Mairesse (1997). This section of the paper presents the model and discusses the problems with using it to measure the rate of returns to $R \& D$.

The Cobb-Douglas production function augmented with a knowledge capital term takes the followng (stylized) form:

$$
Y=A L^{\alpha} A^{\beta} K^{\delta} e^{u}
$$


where $L$ is a measure of labor input, $A$ is ordinary (tangible) capital, $K$ is knowledge (intangible) capital, and $u$ is a disturbance. To implement this equation for estimation using a panel of firms followed over time, take logarithms and write it using $i$ to denote firms and $t$ to denote time:

$$
y_{i t}=\eta_{i}+\lambda_{t}+\alpha l_{i t}+\beta c_{i t}+\gamma k_{i t}+u_{i t}
$$

The lower case letters denote logarithms of the variables in the original model, $\eta_{i}$ denotes a firm specific effect that is constant over time and $\lambda_{t}$ denotes a time-specific effect that is constant across firms. The shock $u_{i t}$ and the firm effect $\eta_{i}$ may possibly be correlated with the current (and future) input levels. In principle, both of these econometric problems can be solved by estimating with GMM on first differences of the equation, provided appropriate instruments are available (Blundell and Bond 1998).

Although equations (1) and (2) are usually labeled production functions, in the case of individual firms they are more properly called revenue production functions. That is, in the absence of firmspecific price deflators, the measure of output $Y$ is the firm-level price multiplied by the quantity sold (or a sum of such terms in the usual case where there is more than one product). This fact implies that $\gamma$ measures the joint contribution of $R \& D$ to productivity and to the prices charged by the firm (which could be declining if $R \& D$ makes the firm more efficient in a competitive market or increasing if $R \& D$ is primarily used to improve quality). But from the perspective of measuring private returns, this is not a problem, because either (cost reduction or product improvement) are outcomes that end up in the bottom line. Nevertheless, it is important that we not confuse these measures with true productivity measures, which remove the effects of R\&D on price. The latter are the relevant concept for social welfare.

Implementing estimation using equation (2) requires construction of a measure of knowledge capital $K$. Beginning with the work conducted during the large NBER project on R\&D, patents, and productivity, Griliches and his co-authors used a conventional declining balance formula for the construction of (real) $K$, by analogy with ordinary investment and capital:

$$
K_{i t}=(1-\delta) K_{i, t-1}+R_{i t}
$$


Although a variety of choices for the depreciation rate have been explored in the past, the choice makes little difference for estimation, and most researchers use the 15 per cent that Griliches had settled on in his work (see Hall and Mairesse 1995 for some experiments with different rates). It is easy to see why this might be the case: assume that R\&D grows over a sufficiently long period at a constant (firm-specific) rate $g_{i}$ and that the knowledge capital $\mathrm{K}$ depreciates at a firmspecific rate $\delta_{i}$. Then one can show that

$$
K_{i t} \cong \frac{R_{i t}}{\delta_{i}+g_{i}} \text { or } \log K_{i t}=\log R_{i t}-\log \left(\delta_{i}+g_{i}\right)
$$

where $R$ denotes real R\&D investment at time $t$ and $\delta$ is a suitably chosen (private) depreciation rate. ${ }^{7}$ As long as the growth rate and depreciation do not change very much within firm over time, they will be incorporated into the firm effect in equation (2), and the estimated elasticity of output with respect to either $K$ or $R$ will be the same, and that for $K$ will not depend on the choice of depreciation rate.

However, although the elasticity of output with respect to R\&D may not be affected by the choice of the depreciation rate, the same is not true of the rate of return derived from the elasticity. To see this, note that the gross and net rates of return to $\mathrm{K}$ are:

$$
\rho^{G} \equiv \frac{\partial Y}{\partial K}=\gamma \frac{Y}{K^{*}} \text { and } \rho=\gamma \frac{Y}{K^{*}}-\delta
$$

Therefore the production function approach to measuring returns requires knowledge of $\delta$ both to compute the correct level of $\mathrm{K}$ and also to convert gross returns to net returns.

Appendix $\mathrm{C}$ presents an alternative method of estimating the gross returns to $\mathrm{R} \& \mathrm{D}$ that is sometimes used, one that includes R\&D intensity on the right hand side of a productivity growth

7 For future reference, I note also that under the assumption of constant depreciation at the firm level, equation (4) implies that the "true" R\&D capital $K^{*}$ ( $K$ computed using correct economic depreciation) is given by the equation cent).

$$
K_{i t}^{*}=K_{i t} \frac{\delta_{i}+g_{i}}{\delta_{i}^{0}+g_{i}} \text {, where } \delta_{i}^{0} \text { is the depreciation rate used to construct the measured } K \text { (usually } 15 \text { per }
$$


equation. The appendix shows that this method produces estimates that are seriously downward biased, unlike those obtained using the production function approach. Although $\rho^{G}$ is measured directly (if incorrectly) using this method, one needs knowledge of $\delta$ to convert it to a net rate, and also to correct for the use of gross $R \& D$ investment rather than net R\&D investment in the equation. Given these problems, I do not use estimates based on this method.

\subsection{Deriving depreciation estimates from the production function}

In this section, I describe how to invert the relationship in equation (5) in order to estimate a depreciation rate given an elasticity estimate and a required net rate of return. ${ }^{8}$ Two possibilities suggest themselves: The first is to make the strong assumptions of perfect competition and pricetaking, set the share of R\&D capital $\left(c_{K} K / p_{Y} Y\right)$ equal to its estimated elasticity, and derive the depreciation rate that will make the equality true. This has a number of disadvantages: these firms are far from perfectly competitive, much of the R\&D is devoted to creating demandenhancing product improvement (which implies nonzero markups), and probably most important, the productivity coefficient is seriously biased upward due to the omission of purchased inputs and materials from the production function.

The alternative is to make the weaker assumption that the firm is a cost minimizer facing a Cobb-Douglas production function with factor-neutral scale and demand effects. In this case the elasticities of the two types of capital (R\&D and tangible) will be proportional to their shares, even though each share will not be equal to its own productivity coefficient. That is, the biases due to scale and markup cancel, which implies the following relationship between the estimated production function elasticities and factor shares:

$$
\frac{\gamma}{\beta}=\frac{c_{K}^{*} K^{*}}{c_{A} A}
$$

$\gamma$ is the output elasticity of true knowledge capital $K^{*}$ and $\beta$ is the output elasticity of tangible capital $A$. The neoclassical cost of capital $c_{J},(J=A, K)$ is given by the following equation:

\footnotetext{
${ }^{8}$ It is helpful to recall that the estimated productivity itself is not greatly affected by the choice of depreciation rate, once industry or firm effects have been controlled for.
} 


$$
c_{J}(t)=p_{J}(t)\left[1-\frac{\left(1-\delta_{J}\right)\left[p_{J}(t+1) / p_{J}(t)\right]}{(1+\rho)}\right]
$$

where $\delta_{J}$ is the appropriate depreciation rate, $p_{j}(t)$ is the price of capital relative to output and $\rho$ is the required rate of return. Given estimates of $\gamma$ and $\beta$, and knowing $c_{A} A$, this relation allows us to compute $c_{K} K$ and compare it with the observed measure of $K$ in order to derive an estimate of the cost of R\&D capital $c_{K}$ and therefore of its depreciation rate.

However, note that both $c_{K}$ and $K$ contain depreciation, the former because the cost of capital includes the cost of its replacement and the latter because the current measured stock depends on past depreciation. Higher depreciation implies a higher true cost of capital but it also implies that we have overestimated $K$, so the true $K\left(K^{*}\right)$ will be lower. The existence of this tradeoff makes identification of the actual depreciation rate from the production function difficult, even if we are willing to make the assumptions necessary for equation (6) to hold. Assuming that the depreciation rate used to construct $K$ was 15 per cent, equation (4) implies the following relationship between $K^{*}$ and $K$ :

$$
\begin{aligned}
& c_{K}^{*} K^{*}=\tilde{p}_{K}\left[1-\frac{\left(1-\delta_{K}\right)\left(1-\Delta \tilde{p}_{K} / \tilde{p}_{K}\right)}{(1+\rho)}\right] \frac{g_{R}+0.15}{g_{R}+\delta_{K}} K \\
& \cong \tilde{p}_{K} K \frac{\left(\rho+\delta_{K}\right)}{\left(g_{R}+\delta_{K}\right)} \frac{\left(g_{R}+0.15\right)}{(1+\rho)}
\end{aligned}
$$

The approximation holds because the year-to-year rate of change in the relative price of $R \& D$ is very small. ${ }^{9}$ Clearly, even under the heroic assumption that the output elasticities of R\&D and ordinary capital are proportional to their shares, $R \& D$ depreciation will be difficult to identify if the growth of $R \& D$ is approximately equal to the interest rate $(\rho)$, as it is for much of my data. Nevertheless, estimates using the relationship in equation (8) and an estimate of $c_{K} * K^{*}$ that is derived from equation (6) are reported in sections 3.3 and 3.4 of the paper.

\footnotetext{
${ }^{9}$ In the implementation reported here, I do take account of this capital gains term, however.
} 


\subsection{Double counting of $R \& D$ inputs}

There is one final measurement issue that needs to be considered if we wish to derive firm-level $R \& D$ rate of return estimates from the existing data on $R \& D$ expenditure and output: the double counting of R\&D inputs. Schankerman (1981) pointed out long ago that because R\&D spending is composed of spending on labor, capital, and materials, these expenditures have already been included in the ordinary input measures of the production function, and the coefficient of R\&D capital therefore has a substantial downward bias. Using a cross section of US manufacturing firms in 1963, he estimated that the magnitude of the downward bias ranged from 0.02 to 0.09 , and was higher in industries with higher R\&D intensities, as theory would suggest. Hall and Mairesse (1995) estimated the downward bias for French manufacturing firms using measured R\&D labor and capital input and found that it was approximately equal to 0.07 .

Schankerman also computed a formula for correcting the bias, but unfortunately it relies on information about the shares of R\&D labor and capital in ordinary labor and capital that is unavailable in our data. ${ }^{10}$ In this paper, I use the fact that the bias appears to be correlated with $R \& D$ intensity to compute a rough adjustment to the coefficient of $R \& D$ capital by including the interaction of $R \& D$ intensity with the $\log$ of $R \& D$ capital to control for the bias. To mitigate problems with simultaneity, $R \& D$ intensity is lagged one period. Table 2 presents estimates with and without this bias correction.

\subsection{Production function estimates}

I present the results of computations based on equations (6) and (8) in Figure 3 and Table 2. Figure 3 presents year by year estimates of the cost of R\&D capital and Table 2 presents production function estimates and the derived costs of capital and depreciation rates that are based on the six five-year balanced panels.

Figure 3 displays four series: the first two are the costs of capital $c_{A}$ and $c_{K}$ computed using the assumed depreciation rates of 10 and 15 per cent respectively and a required net rate of return,

\footnotetext{
${ }^{10}$ Obviously, if these shares were available, we could simply correct the right hand side variables directly.
} 
for which I use the US Treasury Bill rate plus a 5 per cent equity premium (also shown on the graph). The divergence in these series that appears in the mid-1980s is due to differential trends in the relative prices of $\mathrm{R} \& \mathrm{D}$ and ordinary investment. The investment deflator is from NIPA and incorporates the hedonic estimates for the prices of ICT goods, whereas the R\&D deflator is based on the Griliches-Jaffe methodology which uses labor cost and the GDP deflator as components (Hall 1990). The final series shown is the cost of R\&D capital for the median firm derived from equation (6), using the estimated relative productivities of capital and R\&D capital (adjusted for double counting) and measured R\&D capital $K$ rather than (unobserved) true capital $K^{*}$. The derived series is therefore equal to the last expression in equation (8) without the $K$ :

$$
c_{K}^{\text {derived }}=\tilde{p}_{K} \frac{\left(\rho+\delta_{K}\right)}{\left(g_{R}+\delta_{K}\right)} \frac{\left(g_{R}+0.15\right)}{(1+\rho)}
$$

\section{[Figure 3 about here]}

Several things can be noted about this derived cost of $R \& D$ capital: first, recall that it is based on the following assumptions and measurements: 1) static cost minimization with optimal capital stocks; 2) estimated revenue productivity elasticities of R\&D and ordinary capitals; and 3) a cost of ordinary capital based on interest rates plus an equity premium of 5 per cent and depreciation of 10 per cent per annum. This derived cost of R\&D capital is not necessarily the cost the firm actually faces, but the cost implied by the firm's R\&D investment behavior if it is a cost minimizing firm. The two may diverge if static expectations do not hold. Second, until the mid1990s it is lower than a cost of R\&D capital computed using the usual neoclassical formula, which might imply that true depreciation is actually lower than the assumed 15 per cent, except for the fact that lower depreciation also implies that the true cost of capital should be higher [equation (8)]. Third, it increases from about 12 per cent in the late 1970s to almost 25 per cent in the 1990s (with a spike in the years 1999 and 2000 that is due to the apparent productivity of R\&D investment in those years). During the past ten or fifteen years, it is essentially equal to the cost of R\&D capital computed in the conventional way.

The conclusion is that if $R \& D$ investment depreciates throughout the period at the assumed rate of 15 percent, then up until the mid-1980s, firms were investing as though the cost of R\&D capital was much lower than the cost of ordinary capital. The gap between the two costs of 
capital did not close until the early 1990s. This could reflect expectations about the future productivity of such R\&D. However, an alternative interpretation is that the depreciation rate for $R \& D$ investment increased somewhat during the thirty years, raising the effective cost of R\&D capital.

Table 2 shows the results of estimating the production function for the partially balanced panel, estimated for the six 5-year subperiods of the 1974-2003 period. All the regressions included two-digit industry dummies and year dummies. The top panel shows some statistics for the sample: its size, the medians of the real R\&D capital-sales and real R\&D capital-ordinary capital ratios, and the median of the annual real $R \& D$ growth rate during the period. Note that the $R \& D$ capital-capital ratio rises to a maximum of 35 per cent in the early 1990s and then declines again, probably because of exit and entry into and out of the sample. The second panel shows the estimated production function coefficients and their ratio, along with the standard errors of these estimates, and the cost of capital and depreciation rate that they imply [equations (6) and (8)]. The third panel shows the same quantities computed using a regression with the correction for double counting bias. The correction performs surprisingly well, adding approximately 0.1 to the relative elasticity of $R \& D$ capital vis-à-vis ordinary capital in most of the periods.

\section{[Table 2 about here]}

The depreciation rate for each firm is computed from the implied cost of R\&D capital by inverting equation (10) with $\rho$ equal to the Treasury Bill rate plus a 5\% risk or equity premium and $g_{R}$ equal to the firm's R\&D growth rate. The "delta" method is used to compute the standard error of each depreciation rate as a function of the variance of the production function coefficient estimates. Medians across the firms for both the depreciation rate and its standard error are shown in the table.

It is noteworthy that the productivity of $R \& D$ increases much more rapidly than the ratio of the stocks, and does not show a similar decline in the final two periods. As was suggested by Figure 2 , the cost of R\&D capital rises from a low of less than 5 per cent to a high of over 20 per cent over the period (10 per cent to 37 per cent after correcting for double counting), leading to a corresponding increase in the depreciation rate for R\&D of about 8 percentage points. However, although increasing, this depreciation rate is everywhere negative, suggesting appreciation rather 
than depreciation of $\mathrm{R} \& \mathrm{D}$ capital over the period (albeit at a declining rate towards the end of the period).

A number of explanations of the implied negative private obsolescence (that is, appreciation) of R\&D capital are possible. The most obvious is that $R \& D$ capital was indeed expected to increase in productivity during the 1970s and early 1980s, so that firms invested heavily in R\&D even though its current revenue productivity was low; this explanation rests on the presence of substantial adjustment costs in R\&D. Another possibility is that ordinary capital actually had higher private obsolescence rates than 10 per cent, implying a higher cost of capital, which would also raise the derived cost of $R \& D$ capital. However, this would not remove the gap between the two costs of capital. Other explanations include mismeasurement of the revenue productivities or the deflators that are used in the cost of capital computations.

This result that firms behaved as though $R \& D$ productivity was expected to increase during the twenty or so years following 1974 implies that using the production function methodology to estimate the returns to $R \& D$ can be problematic if $R \& D$ investment is not in equilibrium. To put it another way, the ex post production function approach actually produces implications about returns ex ante if we combine it with the observed cost of capital. But another way to look at the ex ante returns is to use an explicitly expectations-based methodology as described in the next main section of the paper. First, however, I present the sectoral estimates of the productivity function.

\subsection{Productivity estimates by sector}

Obviously, the assumption of a common production function for all of manufacturing is a vast oversimplification, and in this section of the paper I relax this assumption by dividing the firms into six broad technology-based sectors and repeating the estimations in Table 2 sector by sector. The sectors are Chemicals and chemical-based industries, Pharmaceuticals and medical instruments, Electrical equipment and engines, Computers, communication equipment, and scientific instruments, Metals and machinery, and Miscellaneous. The precise definitions are given in Table A3 in the appendix. 
Table 3 shows the results of estimating separate production functions for each sector and time period, in five panels: the sample size, the median of real R\&D capital intensity, the R\&D capital coefficient relative to the ordinary capital coefficient and the standard error of this ratio, the cost of $R \& D$ capital that is implied by that ratio, and the median implied depreciation rate for $R \& D$, together with its median standard error. As expected, the R\&D capital intensity varies greatly across sector, from around 0.1 in the miscellaneous (low tech) sector to almost 0.6 in the computing sector. Note that it tends to decline somewhat over the last two periods, which reflects changing sample composition. The relative productivity of R\&D is also highly variable, highest in the later years in the electrical and computing sectors, and lowest in the early years.

\section{[Table 3 about here]}

These estimates also imply highly varying costs of R\&D capital. In the miscellaneous sector, the implied costs are extremely high, reflecting the high relative productivity of $R \& D$ in this sector. Some of this result is due to the fact that there are a few "high technology" industries, such as video games, mixed into this sector, especially in the latter half of the period. It is noteworthy that the lowest implied cost of capital is in the pharmaceutical sector, where investment has been very heavy throughout the period. This sector also has the lowest depreciation rate (highest appreciation rate); for the other sectors depreciation is essentially zero. Thus the sector estimates suggest that depreciation is lower for pharmaceuticals in almost all periods and for electrical and computing in the earlier years, but they also confirm the aggregate finding that depreciation rates estimated from the revenue productivity of $R \& D$ tend to either have the wrong sign or be very close to zero.

\section{Market value}

The second major approach to valuing the output of R\&D investment considered in this paper is more forward-looking, in that it relies on the financial market's assessment of the value of the firm that has undertaken the investment. The focus is therefore on expected returns, rather than realized profits. This approach has its origins in the seminal work of Griliches (1981) and has been applied to data from a number of countries: US (Cockburn and Griliches 1987, Hall 1993a,b, Hall and Kim 1999, Chan et al. 2001), UK (Blundell et al. 1999, Bosworth et al. 2000, 
Toivanen et al. 2002), Australia (Bosworth and Rogers 2001), Europe (Hall and Oriani 2006), and Japan (Nagaoka 2006). Most of these studies have found a clear association between firm market value and R\&D investment, controlling for other firm assets.

The justification for using firm market value as a proxy for $R \& D$ output value is the idea that although on average we might expect that the value of spending another dollar on R\&D would be equal to that dollar, therefore allowing the use of $R \& D$ input as a measure of $R \& D$ value, there are a number of factors that intervene to make this a rather poor measure: first and foremost is the risk of any R\&D program, which leads to considerable dispersion in the value of its output $e x$ post even if all R\&D input is valued at cost ex ante. In addition, the behavior of competitors in the product market or changes in the prices of inputs or the macro-economy will influence the realized value of an $R \& D$ project. At the least, shadow price for $R \& D$ output derived from a value regression incorporates all the information currently available about the likely success or failure of the sunk R\&D investments in generating future profits for the firm.

Griliches' 1981 approach to the problem of valuing R\&D output was grounded in the theory of hedonic prices: the central idea was that a firm could be considered as a bundle of assets, both tangible (physical capital and inventories), and intangible (R\&D assets or knowledge stock, reputation, and so forth). To compute the shadow price of an asset at any point in time, one could therefore regress the prices or values of a set of firms on their portfolio of assets of different types, and interpret the slope coefficient of any particular type of asset as its marginal shadow value. When implementing this idea, most researchers have followed Griliches' original article and used a first order approximation to the value of the assets, sometimes in logarithmic (CobbDouglas) form, but usually in a simple additive specification. The equation estimated looks like this:

$$
\begin{aligned}
\log V_{i t} & =\log \left[\alpha_{t} p_{i t}^{I} A_{i t}+\gamma_{t} p_{i t}^{R} K_{i t}\right]+\varepsilon_{i t} \\
\text { or } \log Q_{i t} & \equiv \log \left(V_{i t} / p_{i t}^{I} A_{i t}\right)=\log \alpha_{t}+\log \left[1+\frac{\gamma_{t}}{\alpha_{t}}\left(\frac{p_{i t}^{R} K_{i t}}{p_{i t}^{I} A_{i t}}\right)\right]+\varepsilon_{i t}
\end{aligned}
$$


where $V_{i t}$ denotes the market value of firm $i$ at time $t, p_{i t}^{I} A_{i t}$ denotes its (nominal) tangible assets, and $p^{R}{ }_{i t} K_{i t}$ denotes the (nominal) R\&D or knowledge asset. ${ }^{11}$ The logarithmic form of the equation is often simplified using the $\log (1+\varepsilon) \approx \varepsilon$ approximation to linearize the model.

This methodology allows the measurement of the shadow value of $R \& D$, provided one can construct a measure of the R\&D asset. However, nothing in the theory of hedonics suggests that the measured shadow value of R\&D capital should be constant across time, or even across industries. In fact, our interest in the exercise is driven by the fact that it will not be constant. ${ }^{12}$ In practice, both coefficients $\left(\alpha_{t}\right.$ and $\left.\gamma_{t}\right)$ tend to fluctuate a great deal over time and it is not clear how to interpret the fluctuations. $\alpha_{t}$ represents the overall premium or discount in the market for ordinary capital assets and $\gamma_{t}$ the premium or discount for knowledge (R\&D) assets.

When implementing the above methodology, there is an obvious problem in constructing the asset associated with $R \& D$, namely, how should one add up past $R \& D$ investments in order to construct this measure? Usually a declining balance formula [equation (3)] is used, with $\delta$ set equal to 15 per cent. Although this value may be appropriate on average, in many individual firms and industries, depreciation of past R\&D stock in any given year can deviate considerably from 15 per cent and this deviation will show up in the estimated value of $\gamma_{t}$. Conceptually, the correct measure of the $\mathrm{R} \& \mathrm{D}$ asset in the denominator (the book value) is its replacement cost. But what does this mean? In the case of a machine or tangible asset, the meaning is obvious - it is the cost of acquiring one just like it or of manufacturing a new one. But replacing the knowledge stock created by $R \& D$ is quite a different matter: it may be essentially free, if the

\footnotetext{
${ }^{11}$ Most empirical researchers, myself included, write this equation without the price terms, implicitly assuming that $A$ and $K$ are measured in nominal returns. I depart from this practice here to make the notation consistent with that of the theoretical model of Hayashi and Inoue discussed later in the section.

${ }^{12}$ Hedonic regressions often give rise to a well-known identification problem because they are based on market equilibrium data (S. Rosen 1974, Brown and H. Rosen (1982)). Ekeland, Heckman, and Nesheim (2003) discuss this issue and show that in the linear-quadratic model of consumer preferences and production with worker and firm heterogeneity, the linear hedonic model identifies consumer preferences (demand for labor) when workers are homogeneous and worker preferences (supply of labor) when consumers are homogeneous. In our setting, that would correspond to assuming that investors are homogeneous in their taste for firms so that what we are estimating is the supply price of R\&D assets, which varies across firms because of heterogeneous skills and adjustment costs. The use of this assumption seems somewhat more reasonable in the setting here than in many other hedonic applications.
} 
stock is simply to be duplicated within the firm, that is, spread over more output. It may be low cost, if it is simply to be imitated or rediscovered. It may be high cost, if the corresponding invention is patented and another firm wishes to enter the market and reproduce it, either by taking out a license, or by inventing around the patent.

In effect, the knowledge stock that matters for the firm is that which generates privately appropriable returns. From the perspective of $Q$ theory, when the depreciation of knowledge assets is high and therefore $Q$ is low, either the book value of the knowledge asset should have been lower (implying that $K$ should have been constructed using a higher $\delta$ ) or its market value should be lower (implying that the estimated $\gamma_{t}$ will be lower). Although time-varying (and endogenous) depreciation rates can also be a property of ordinary tangible assets, in fact they are much less common because many of these assets trade on a second hand market, which implies that their "market" value is much less volatile and also that it may not vary as much across industries. The problem with the $R \& D$ asset variable is that it is often quite specialized and that once past investment has been written off by the emergence of a better competing product, it has little residual private value. Put simply, the lack of data from a secondhand market for R\&D assets means that an estimate of the market-to-book value ratio is not enough to inform us about market value or book value separately without further assumptions.

This aspect of R\&D capital also implies that valuation of the asset it creates can be highly variable across firms and time. More importantly, it implies that it is not plausible to try to incorporate "true" economic depreciation into the book estimate of R\&D capital. It would be far better to try to estimate depreciation from the valuation itself. However, there is a difficulty, because we will need some kind of depreciation to construct a stock from past R\&D flows. Simply adding the flows up is not attractive because it places too much weight on R\&D done long ago and because the stock then becomes quite sensitive to the number of time periods over which the firm has been observed. So the best we can do is what was originally done by Griliches (1981) and followed by his successors: use a plausible depreciation rate such as 15 per cent and then try to infer the true value from the estimated shadow value of the R\&D. In the next section of the paper this is what is done. 
In appendix B, I present a sketch of a theoretical model due to Hayashi and Inoue (1991), which provides a framework for interpretation of the hedonic market value regression results. Under the usual $Q$ model assumptions and an additional assumption that the market value equation is weakly separable so that there is a single capital aggregator, Appendix B shows that the estimating equation for a firm with two capitals, tangible and knowledge, is the following:

$$
\log Q_{i t}=\log \alpha_{t}+\log \left[1+\frac{\gamma_{t}}{\alpha_{t}} \frac{\left(1-\delta_{R}\right) p_{i t}^{R} K_{i t}}{\left(1-\delta_{I}\right) p_{i t}^{I} A_{i t}}+\frac{\lambda_{t}}{\alpha_{t}} \varphi^{*}\left(K_{i t} / A_{i t}\right)\right]+\varepsilon_{i t}
$$

In this equation $p^{R} K$ and $p^{I} A$ are the nominal values of beginning of period capital stocks, $\mathrm{K}$ and A are real values, $\alpha_{t}$ corresponds to overall market movements in Tobin's $Q, \gamma_{t} / \alpha_{t}$ is the relative shadow value of $\mathrm{R} \& \mathrm{D}$ capital, and $\varphi^{*}(K / A)$ is a capital aggregator, constructed as a Divisia index of $K$ and $A$, using their respective costs of capital (see the appendix for details), with $\lambda_{t} / \alpha_{t}$ its coefficient. There are two K terms: if the depreciation rates are accurate, the first term simply corrects the assets used to construct $Q$ for the omission of R\&D capital, which implies that $\gamma_{t} / \alpha_{t}$ should be unity. The second term represents the contribution of variations in R\&D capital intensity to deviations of the corrected Q ratio from unity. Thus $\lambda_{t} / \alpha_{t}$ should also be zero in equilibrium if everything is correctly measured and there are no unanticipated shocks that impact R\&D-intensive firms differentially.

Comparing equations (10) and (11), we see that there are two differences: first, because the model and data are discrete time, the assets need to be corrected by one minus their depreciation rates, to capture the fact that the appropriate dating is the same as that of market value, end of period. Second, the theoretical model includes the capital aggregator term, $\varphi^{*}(K / A)$, whose coefficient is a function of the random (exogenous to the firm at time $t$ ) shocks driving the valuation process. Unfortunately the model provides no further information about or predictions of the magnitude of this coefficient.

In Appendix B of the paper, I explore the use of equation (11) to estimate the market value equation and compare the results to the simple specification in equation (10). The results show that including a capital aggregator term in the model increases the coefficient of the K/A ratio towards unity, and that the aggregator term itself has a negative coefficient, implying negative 
rents to $R \& D$ in all periods. However, recall that interpreting these results requires assuming that $\mathrm{K}$ was constructed using an accurate measure of $\mathrm{R} \& \mathrm{D}$ depreciation, which is unlikely. Therefore, I chose to use the model in equation (11) as a guide for the interpretation of the usual hedonic equation estimates rather than directly as a structural model. The principal interpretive change suggested by this model is that because the data is discrete time data, measured capitals should be depreciated before inclusion in a Tobin's q equation. In effect, from the perspective of forward looking market valuation, capital depreciation takes place instantaneously at the end of each time period.

\subsection{Market value estimates}

In Tables 4 and 5 the results of estimating the usual hedonic regression [equation (10) or equation (11) without the $\varphi^{*}$ term] estimation are shown, along with the estimates of the R\&D depreciation rate that are implied by the assumption that the valuations of an additional dollar spent on tangible or intangible assets are equal. Table 4 shows estimates for all of manufacturing and Table 5 for each of the 6 subsectors; both are for five year balanced panels identical to those used in Tables 2 and 3. In Table 4, three different estimation methods are used for comparison: ordinary least squares (OLS) and least absolute deviations (LAD) on the linear version of equation (10) and nonlinear least squares (NLS) on the version that does not use the $\log (1+\varepsilon)$ approximation. The top panel of the table shows a few characteristics of the samples, including the median of the R\&D growth rates that will be used to construct the estimates of the depreciation rate. Nominal K/A and the R\&D growth rate increase until the mid-1990s and then fall off a bit in the last period. By the end of the period, the median R\&D capital stock is over one-third of the total tangible assets, having grown from about one-fifth in the mid-1970s.

\section{[Table 4 about here]}

The bottom three panels of Table 4 show the estimated K/A coefficient from a regression that also includes 14 industry dummies and dummies for each year. In general, the LAD estimates are higher than the OLS estimates and the NLS estimates are higher still. ${ }^{13}$ The robust standard

\footnotetext{
${ }^{13}$ This is consistent with kernel regression estimates (not shown) which indicate an approximately linear relationship for values of K/A between 0.01 and 1, but considerably flatter below and above that interval. Below $1 \%$
} 
errors are roughly comparable across all the estimates and fairly small. Given the large size of the K/A ratios, the preferred specification is that estimated by NLS which does not rely on approximating the original equation. These estimates are reasonably consistent with earlier work using the same data, showing an increased valuation of R\&D in the late 1970s and early 1980s followed by a precipitous decline in the 1980s. However, they also show a substantial recovery during the mid-1990s, one that does not reflect declining R\&D (see the first panel) but is more likely to be due to an increase in technological opportunity.

\subsection{Estimating depreciation from market value}

To estimate depreciation from these results, I assume that the markets for both types of capital are in equilibrium, which has two implications. First, R\&D capital is valued equally with tangible capital (that is, the coefficient of nominal $K / A\left(\gamma_{t} / \alpha_{t}\right)$ is unity). Second, $\lambda_{t}$ in equation (11) is zero (that is, there are no rents accruing from the capitals above and beyond the normal return). These are admittedly strong assumptions: probably the most significant problem with them is that they ignore the adjustment costs that may be associated with R\&D programs. However, the effect of adjustment costs cannot really be distinguished from changes in depreciation using the data available here.

Given these two assumptions, one can show that the following holds:

$$
\frac{\left(1-\delta_{R}\right) p_{i t}^{R} K_{i t}^{*}}{\left(1-\delta_{I}\right) p_{i t}^{I} A_{i t}}=\frac{\hat{\gamma}_{t}}{\hat{\alpha}_{t}} \frac{p_{i t}^{R} K_{i t}}{p_{i t}^{I} A_{i t}} \cong \frac{\hat{\gamma}_{t}}{\hat{\alpha}_{t}} \frac{p_{i t}^{R} K_{i t}^{*}}{p_{i t}^{I} A_{i t}} \frac{\left(\delta+g_{R}\right)}{\left(\delta_{R}+g_{R}\right)}
$$

The above derivation uses the (approximate) relationship in equation (4) to derive the "true" knowledge capital $K^{*}$ from measured capital $K$. Using equation (12), the implied depreciation rate for $\mathrm{R} \& \mathrm{D}$ is computed as a function of the estimated coefficient of $\left(p_{K} K / p_{A} A\right)$ :

$\mathrm{K}$ is essentially irrelevant for value (these observations are treated as zero) and above $100 \%$ the relationship is flatter. The log transformation used in the NLS model approximates this kind of behavior well. The average measured elasticity (as opposed to the coefficient) from the NLS estimates is approximately the same as the OLS coefficient. 


$$
\hat{\delta}_{i t}=\frac{\left(.15+g_{i t}\right)-\left(1-\delta_{I}\right) g_{i t}\left(\hat{\gamma}_{t} / \hat{\alpha}_{t}\right)}{\left(.15+g_{i t}\right)+\left(1-\delta_{I}\right)\left(\hat{\gamma}_{t} / \hat{\alpha}_{t}\right)}
$$

$\delta$ and its standard error are computed for each firm using this equation, conditioning on the observed firm-level growth rate of $\mathrm{R} \& \mathrm{D}$. The median value and the median standard error are shown in the tables. These depreciation rates are large, but not implausible: they follow the same pattern as the coefficient (as they should), and they indicate that up to 35\% of R\&D might have been written off in any one year during the 1980s; the average rate for the whole thirty years is 27.5 per cent, somewhat higher than the 15 per cent usually used. ${ }^{14}$

Table 5 gives a hint of the source of these relatively high depreciation rates, although the estimates are very imprecise in places. This table shows depreciation estimates for each of the six sectors and six periods that are derived from nonlinear least squares estimates of the model. The overall ranking of the sectors in terms of increasing $R \& D$ depreciation is Pharmaceuticals and medical instruments, Chemicals, Miscellaneous, Computers, communication equipment, and scientific instruments, Metals and machinery including autos, and Electrical machinery including electronic components and aircraft, which seems roughly consistent with what we know about the pace of technical change in those sectors.

It is interesting to compare the drugs and computers sectors, which are of course the ones with the highest (and most variable across firms) R\&D intensity. These two sectors exhibit very different depreciation patterns. For drugs and medical instruments, R\&D depreciation is roughly $15 \%$, somewhat lower in the mid-1970s and mid-1980s and higher thereafter. On the other hand, the computers and instruments sector has write-offs of $30 \%$ or higher during the 1979-1998 period, with a high of almost $50 \%$ in the mid-1980s. It is not hard to see this as the reaction of investors in the sector to the personal computer and internet revolution, which was accompanied

\footnotetext{
${ }^{14}$ In fact, equation (12) allows us to derive a formula for the coefficient of $p_{K} K / p_{A} A$ under the assumption that tangible and intangible capitals are priced the same in the market. This formula would allow estimation of the "true" depreciation rate directly using nonlinear least squares. The choice between this method and the two-step method used in the text essentially turns on whether one prefers to assume that the coefficient of $p_{K} K / p_{A} A$ is the same for all firms (the method in the text) or depreciation is equal for all firms. I preferred the former assumption, although I also estimated the nonlinear least squares model under the latter assumption. The results are similar, with slightly lower depreciation rates in many (but not all) cases.
} 
by a number of exits of older computer firms and restructuring of those that remained. The dotcom boom seems to have restored the depreciation rate to something more normal, although still somewhat higher than that for the pharmaceutical sector. Thus there is some indication that the private returns depreciation rates derived from market value equations for these two sectors capture something of the different nature of competition in the sectors, with pharmaceuticals simultaneously having a longer product cycle, and a greater ability to exclude competitors over a longer period. Both of these features suggest that the private $R \& D$ depreciation rate should be lower for this sector than for computers and instruments.

\section{[Table 6 about here]}

Turning to the other sectors, Chemicals looks a lot like Pharmaceuticals, but with the exception of fairly high depreciation in the late 1980s-early 1990s, a write-off that also occurred in the metals, machinery, and transportation equipment sector somewhat earlier. This is the period of leveraged buyouts and shrinkage of the traditional rustbelt industries in the United States, clearly reflected in their $R \& D$ valuations (also notice the decline in number of observations as firms exit from these industries, mostly via merger). The electrical industry did not suffer as much in the early part of this period, but its valuations fell later, which suggests a speed-up of competition or a change in industry composition, possibly related to the growth of the computing sector.

From these results I conclude that the market value equation is capable of giving an approximate indication of relative depreciation, but that the estimates are probably not precise enough for measuring a rate of return, at least at the sectoral level. They may also be systematically high, which is what one might expect if the coefficient estimates are biased downward, either because of measurement error, or because they have not been adjusted for the fact that R\&D investment may be riskier than ordinary investment.

\section{Conclusions}

This paper has presented a detailed exploration of the consequences of variable and unknown private depreciation rates of $R \& D$ capital for the measurement of the rate of return to $R \& D$, going further down one of the many paths left open for exploration by Zvi Griliches in his final monograph published in 2000. Although the paper has focused specifically on R\&D, the results 
are applicable to returns measurement for any investment where the capital created is not traded on a secondhand market (so there is no independent measure of depreciation) and where the capital does indeed depreciate, at least from the perspective of its "owner." In particular, the discussion would apply to innovation investments more broadly defined.

The previous literature had used three different methods of computing the returns to $R \& D$ econometrically: regressing output on $R \& D$ intensity, regressing output on $R \& D$ using a production function, and regressing firm market value on R\&D. An appendix to the paper showed that the first method produces results that are seriously downward biased if R\&D depreciation is of any concern. The other two methods do not suffer as much from this problem in actual estimation, but they both require estimates of $\mathrm{R} \& \mathrm{D}$ depreciation in order to compute a rate of return from the estimates. In the absence of such estimates, the approach to analysis suggested was to assume "normal" rates of return and compute the implied depreciation rate.

These estimates were therefore obtained in two different ways: first, by assuming the firms invest in $\mathrm{R} \& \mathrm{D}$ until its relative marginal product equals the relative cost of capital and deriving the implied depreciation rate, and second by assuming that the market values properly depreciated $R \& D$ capital one for one with ordinary capital and deriving the implied depreciation rate from that fact. For the manufacturing sector during the entire 1974-2003 period, these two methods yielded quite different estimates of $R \& D$ depreciation: negative 6 per cent from $R \& D$ productivity and 28 per cent from market value. At the broad industry level, there is little systematic relationship between results from the two methods, with the exception that depreciation rates are lower in pharmaceuticals and somewhat higher in electrical/computing.

Thus we are no further in resolving the conundrum identified by Griliches, although we have perhaps a better understanding of its origins. The assumptions required to perform the computations in this paper are heroic and the heterogeneity across the firms substantial, which helps to explain the variability of the results to some extent. Nevertheless, the persistent gap between productivity and market value results requires some explanation. In order to derive depreciation from the productivity results I had to assume that the firms' current level of R\&D stock was chosen so that its marginal product covered the required rate of return plus depreciation. On the other hand, to derive depreciation from market value I had to assume that 
financial markets were efficient and that the firm had optimized its choice of R\&D capital. Both sets of assumption ignore adjustment costs in R\&D capital, which may be substantial.

One way we might rationalize the results using adjustment costs or disequilibrium arguments is to note that during the 1970 s and early 1980s, the productivity of R\&D capital relative to ordinary capital was rising faster than the ratio of their shares, yielding an implied cost of R\&D capital that was relatively low. This translated into a relatively high valuation for existing $R \& D$ capital, implying that investing in R\&D was a "good bet". The adjustment cost story simply argues that it was not possible for firms to invest quickly enough to bring the relative productivity down and reduce the valuation of R\&D investments.

Following this period is one (roughly 1984-1993) where the shares and relative productivity are roughly equal and the derived cost of $R \& D$ capital is around 20 per cent. However, the aggregate results mask considerable variability across sector, with high implied costs of capital in electrical, metals and machinery, and miscellaneous sectors. These high effective costs of capital may have reflected high relative productivity for $R \& D$, but could also imply rapid depreciation or obsolescence of R\&D in these sectors. That is, a high cost of capital can be due either to a high required rate of return or to a high depreciation rate. At the same time, the relative value of R\&D capital was in the 0.5-0.6 range and substantial writeoffs (high depreciation) of R\&D took place except in pharmaceuticals and to some extent, chemicals.

In the late 1990s and early 2000s, the relative productivity of R\&D starts to increase again, this time at a level above the relative share ratio across all sectors except for pharmaceuticals. The implication is that the cost of $\mathrm{R} \& \mathrm{D}$ capital has increased. At the same time, the relative market valuation of $R \& D$ returned to the level of the early 1980s and the implied depreciation rate of R\&D has fallen. This suggests at least two (related) possibilities: the required rate of return to $R \& D$ may have risen or adjustment costs are preventing $R \& D$ investment from increasing fast enough to bring down its productivity.

Two further conclusions about the rate of return to R\&D can be drawn from the results presented here: first, private depreciation is likely to be more variable and higher than the 15 per cent normally assumed. Second, researchers and policy analysts should be strongly cautioned against 
treating the rate of return to $R \& D$ as a parameter: clearly it is the complex outcome of a moving equilibrium.

Although the approach used in this paper to estimate the depreciation of R\&D capital is a good first approximation, one cautionary note needs to be sounded: Both methods of estimation relied on the assumption that within-firm depreciation was approximately constant in order to use the simple "cap rate" formula to correct the mis-estimated R\&D capital and derive a (median across firms) depreciation rate that varied over time. But clearly that introduces some inconsistency into the analysis, in that the assumption of constant depreciation rates for each firm is inconsistent with time-varying depreciation rates in the aggregate, unless the source of variability comes entirely from changing sample composition. The present paper leaves this problem to be solved by future research. 


\section{References}

Blundell, R., and S. Bond (1998): "GMM estimation with persistent panel data: An application to production functions," London, UK: IFS Working Paper 9904, available at http://www.ifs.org.uk/wps/wp9904.pdf

Blundell, R., R. Griffith, and J. Van Reenen (1999): "Market Share, Market Value and Innovation in a Panel of British Manufacturing Firms," Review of Economic Studies, 66, 529554.

Bosworth, D., and M. Rogers (2001): "Market Value, R\&D and Intellectual Property: An Empirical Analysis of Large Australian Firms," The Economic Record, 77, 323-337.

Bosworth, D., A. Wharton, and C. Greenhalgh (2000): "Intangible Assets and the Market Valuation of UK Companies: Evidence from Fixed Effects Models," Oxford, UK: Oxford Intellectual Property Research Centre Working Paper.

Brown, J., and H. Rosen (1982): "On the Estimation of Structural Hedonic Price Models," Econometrica 50: 765-769.

Chan, S. H., J. D. Martin, and J. W. Kensinger (1990): "Corporate Research and Development Expenditures and Share Value," Journal of Financial Economics.

Chan, L. K. C., J. Lakonishok, and T. Sougiannis (2001): “The Stock Market Valuation of Research and Development Expenditures," Journal of Finance 56 (6):2431-2456.

Cockburn, I., and Z. Griliches (1987): "Industry Effects and Appropriability Measures in the Stock Market's Valuation of R\&D and Patents." American Economic Review, 78, 419-423.

Ekeland, I., J. J. Heckman, and L. P. Nesheim (2003): "Identification and Estimation of Hedonic Models," NBER Working Paper No. 9910 (August).

Griliches, Z. (1958): "Research Costs and Social Returns: Hybrid Corn and Related Innovations," Journal of Political Economy 66 (5): 419-431. 
Griliches, Z. (1979): "Issues in Assessing the Contribution of Research and Development to Productivity Growth," Bell Journal of Economics 10 (1): 92-116.

Griliches, Z. (1980): "Returns to Research and Development Expenditures in the Private Sector," in Kendrick, J. W., and B. N. Vaccara (eds.), New Developments in Productivity Measurement and Analysis, Chicago: University of Chicago Press, 419-454.

Griliches, Z. (1981): "Market Value, R\&D, and Patents," Economic Letters, 7, 183-187.

Griliches, Z. (ed.) (1984): R\&D, Patents, and Productivity, NBER Conference volume, Chicago: University of Chicago Press.

Griliches, Z. (1996): R\&D and Productivity: The Econometric Evidence, Chicago: Chicago University Press.

Griliches, Z. (2000): R\&D, Education, and Productivity: A Retrospective, Cambridge, MA: Harvard University Press.

Griliches, Z., and J. Mairesse (1997): "Production functions: the search for identification," S. Strom (ed.) Essays in Honour of Ragner Frisch, Econometric Society Monograph Series, Cambridge University Press.

Griliches, Z., B. H. Hall, and A. Pakes (1991): "R\&D, Patents, and Market Value Revisited: Is There a Second (Technological Opportunity) Factor?" Economics of Innovation and New Technology, 1, 183-202.

Griliches, Z., and D. W. Jorgenson, “The Explanation of Productivity Change," Review of Economic Studies 34 (3): 249-283.

Hall, B. H. (2004): “A Note on Measurement Error and Proxy Variables,” available at http://www.econ.berkeley.edu/ bhhall/papers/BHH04_measerr.pdf

Hall, B. H. (1993a): "Industrial Research during the 1980s: Did the Rate of Return Fall?" Brookings Papers on Economic Activity, Micro (2), 289-344.

— (1993b): "The Stock Market Valuation of R\&D Investment during the 1980s," American 
Economic Review, 83, 259-264.

(1990): “The Manufacturing Sector Master File: 1959-1987.” NBER Working Paper No. 3366.

Hall, B. H., Z. Griliches, and J. A. Hausman (1986): "Patents and R\&D: Is There a Lag?"

International Economic Review 27: 265-83.

Hall, B. H., and J. Mairesse (1995): "Exploring the relationship between R\&D and productivity in French manufacturing firms," Journal of Econometrics 65: 263-293.

Hall, B. H., and J. Mairesse (2005): "Testing for Unit Roots in Panel Data: An Exploration Real and Simulated Data," in Andrews, D., and Stock, J. (eds.), Identification and Inference in Econometric Models: Essays in Honor of Thomas J. Rothenberg, Cambridge University Press.

Hall, B. H., and R. Oriani (2006): "Does the Market Value R\&D Investment by European Firms? Evidence from a Panel of Manufacturing Firms in France, Germany, and Italy," International Journal of Industrial Organization 24: 971-993.

Hayashi, F. (1982): “Tobin’s Marginal Q and Average Q: A Neoclassical Interpretation,” Econometrica 50 (1): 213-224.

Hayashi, F., and T. Inoue (1991): "The Relation between Firm Growth and Q with Multiple Capital Goods: Theory and Evidence from Panel Data on Japanese Firms," Econometrica 59 (3): 739-753.

Mairesse, J., and P. Mohnen (1990): "Recherche-développement et productivité, un survol de la littérature économétrique," Économie et Statistique, 237-238, 99-108.

Mairesse, J. and M. Sassenou (1991): "R\&D and productivity: a survey of econometric studies at the firm level", STI Review (OECD), 8, 9-46.

Mansfield, E. (1965): "Rates of Return from Industrial R\&D,” American Economic Review, 55, 310-322.

Nagaoka, S. (2006): "R\&D and the Market Value of Japanese Firms in the 1990s," Journal of 
the Japanese and International Economies 20: 155-176.

National Science Foundation, Division of Science Resources Studies (2006): Research and Development in Industry: 2002, NSF 06-322, Project Officer and Principal Author, Raymond M. Wolfe (Arlington, VA).

Rosen, S. (1974): "Hedonic Prices and Implicit Markets: Product Differentiation in Price Competition," Journal of Political Economy 82: 34-55.

Schankerman, M. (1981): "The Effects of Double-Counting and Expensing on the Measured Returns to R\&D," Review of Economics and Statistics 63 (3): 454-458.

Terleckyj, N. (1958): “Factors Underlying Productivity: Some Empirical Observations,” Journal of the American Statistical Association, 53, 593.

Terleckyj, N. (1974): Effects of R\&D on the Productivity Growth of Industries: An Exploratory Study. Washington, D.C.: National Planning Association.

Toivanen, O., P. L. Stoneman, and D. Bosworth (2002): "Innovation and the Market Value of UK Firms, 1989 - 1995," Oxford Bulletin of Economics and Statistics, 64, 39-62.

Wildasin, D. (1984): “The q Theory of Investment with Many Capital Goods," American Economic Review 74: 203-210. 
Figure 1

Productivity and market value of R\&D in US manufacturing firms

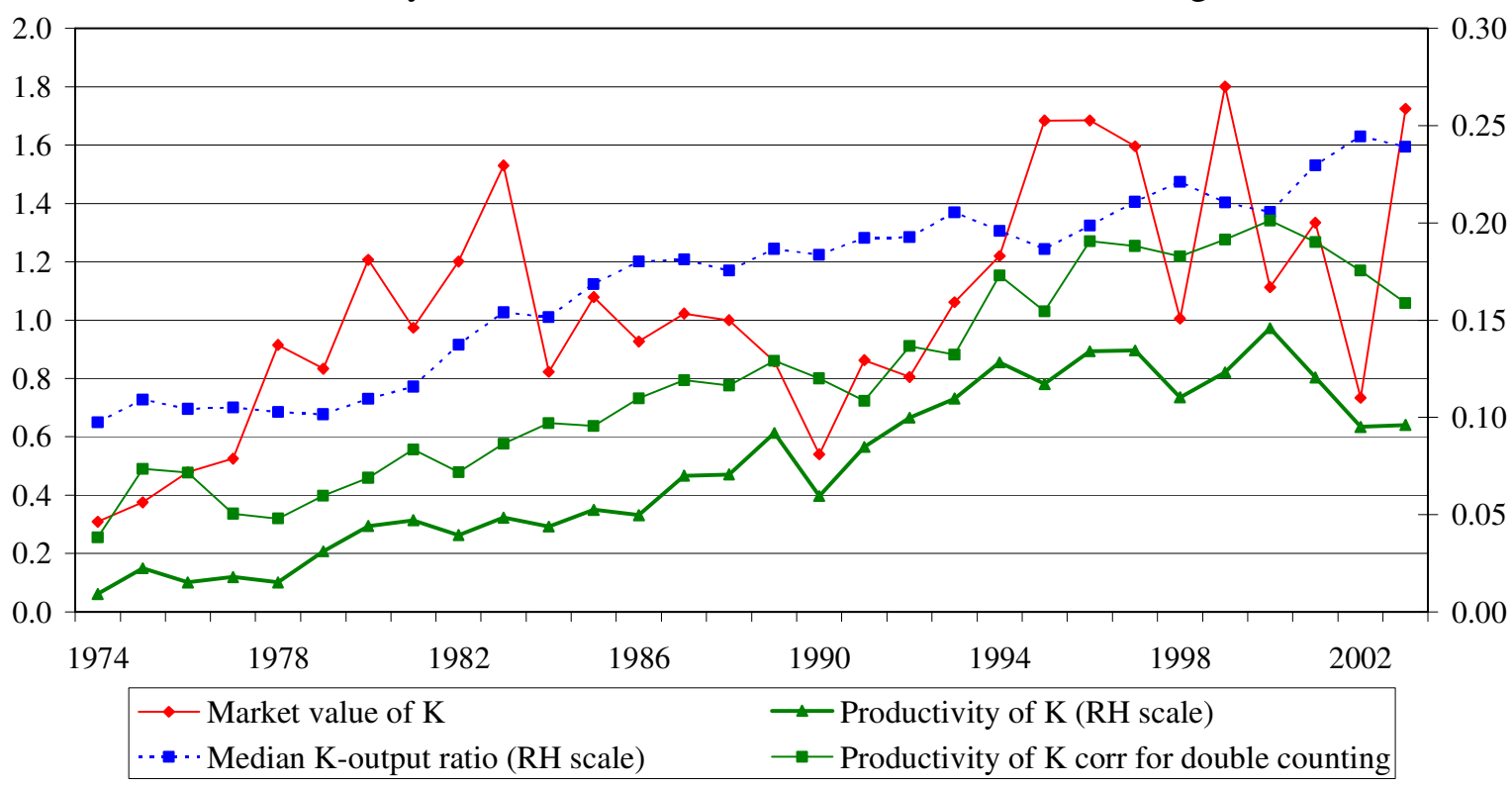

Figure 2

Productivity and market value of R\&D in US manufacturing firms

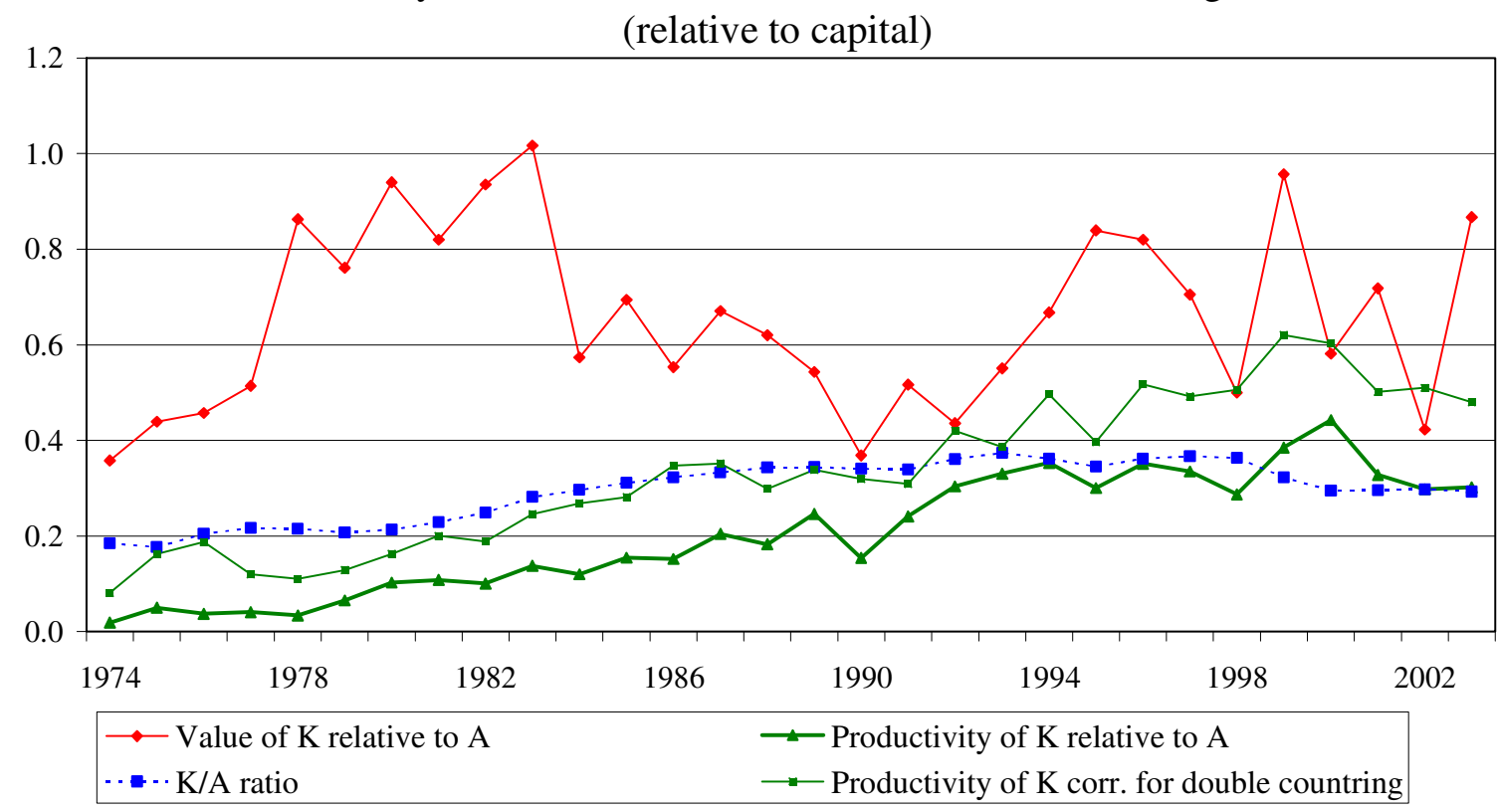


Figure 3

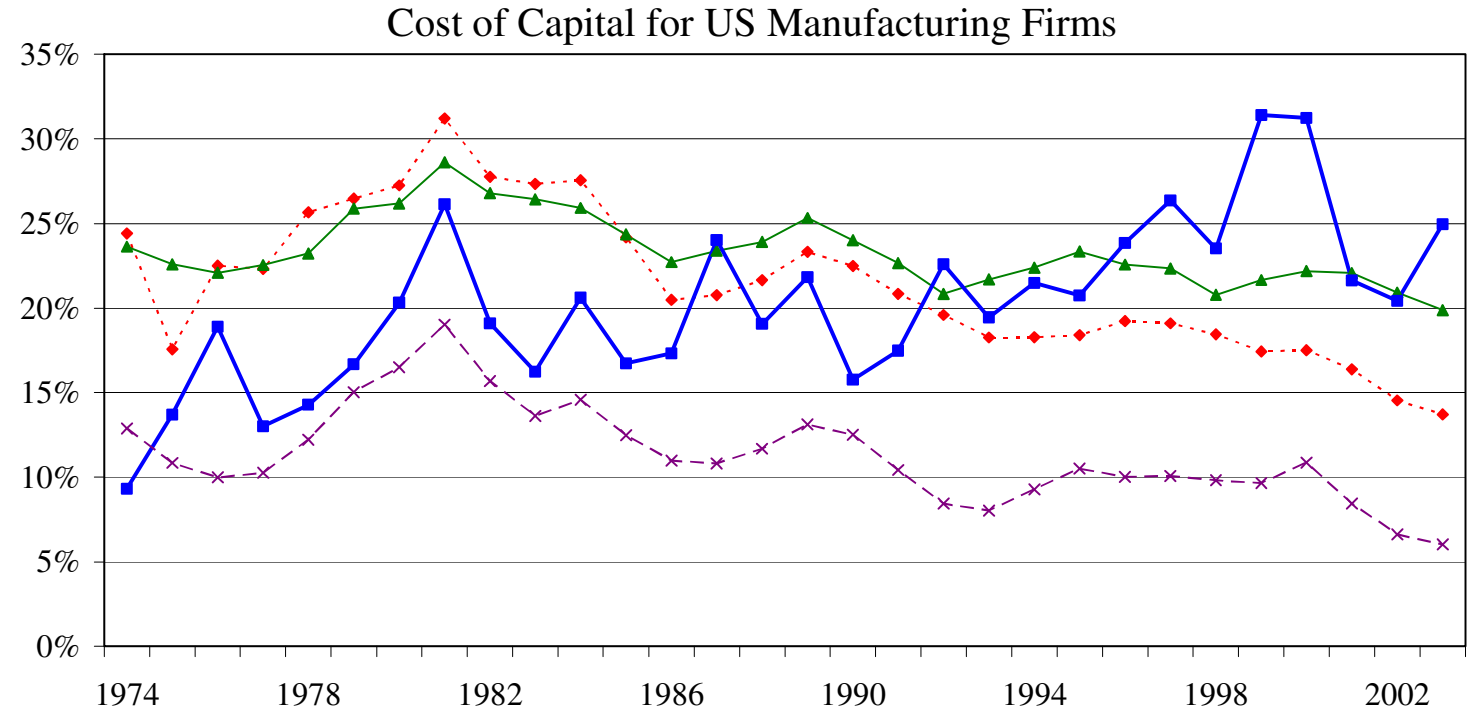

- Cost of ordinary capital $\rightarrow-$ Cost of R\&D capital

$\rightarrow-$ Derived cost of R\&D capital for the median firm -*- Interest rate plus risk premium 
Table 1

Sample statistics 1974-2003

\begin{tabular}{|c|c|c|c|c|c|c|}
\hline & Mean & Std. dev. & Median & IQ range & Minimum & Maximum \\
\hline \multicolumn{7}{|c|}{ Unbalanced panel: 28937 observations } \\
\hline Sales* & 1778 & 7653 & 178 & 794 & 2.0 & 174710 \\
\hline Employment (1000s) & 10.1 & 33.6 & 1.5 & 5.9 & 0.1 & 876.8 \\
\hline Capital stock (A)* & 1070 & 4680 & 77 & 395 & 0.7 & 141190 \\
\hline $\mathrm{R} \& \mathrm{D}$ stock $(\mathrm{K})^{*}$ & 276 & 1436 & 24 & 86 & 0.0 & 43011 \\
\hline A-sales ratio & $54.8 \%$ & $31.3 \%$ & $47.5 \%$ & $29.0 \%$ & $3.3 \%$ & $498.9 \%$ \\
\hline K-sales ratio & $24.1 \%$ & $32.2 \%$ & $14.3 \%$ & $24.1 \%$ & $1.0 \%$ & $486.5 \%$ \\
\hline R\&D-sales ratio & $5.3 \%$ & $7.7 \%$ & $2.8 \%$ & $5.5 \%$ & $0.1 \%$ & $99.1 \%$ \\
\hline Tobin's q = V/A & 2.84 & 3.58 & 1.83 & 1.74 & 0.12 & 70.59 \\
\hline Tobin's $\mathrm{q}=\mathrm{V} /(\mathrm{A}+\mathrm{K})$ & 1.98 & 1.81 & 1.45 & 1.21 & 0.10 & 19.93 \\
\hline \multicolumn{7}{|c|}{ Balanced panel: 16750 observations } \\
\hline Sales* & 2518 & 9538 & 300 & 1350 & 5.1 & 164843 \\
\hline Employment (1000s) & 14.2 & 41.6 & 2.5 & 10.4 & 0.1 & 876.8 \\
\hline Capital stock $(\mathrm{A})^{*}$ & 1487 & 5685 & 133 & 696 & 1.9 & 141190 \\
\hline $\mathrm{R} \& \mathrm{D}$ stock $(\mathrm{K})^{*}$ & 402 & 1823 & 37 & 153 & 0.2 & 43011 \\
\hline A-sales ratio & $54.6 \%$ & $27.8 \%$ & $48.1 \%$ & $26.9 \%$ & $5.6 \%$ & $460.8 \%$ \\
\hline $\mathrm{K}$-sales ratio & $20.9 \%$ & $22.0 \%$ & $13.9 \%$ & $21.3 \%$ & $1.0 \%$ & $332.4 \%$ \\
\hline R\&D-sales ratio & $4.4 \%$ & $5.0 \%$ & $2.7 \%$ & $4.6 \%$ & $0.1 \%$ & $83.8 \%$ \\
\hline Tobin's q = V/A & 2.48 & 2.69 & 1.75 & 1.51 & 0.12 & 50.67 \\
\hline Tobin's q $=\mathrm{V} /(\mathrm{A}+\mathrm{K})$ & 1.85 & 1.56 & 1.41 & 1.11 & 0.10 & 19.43 \\
\hline
\end{tabular}

*Millions of $\$ 1996$ 
Table 2

Production function estimates

\begin{tabular}{lcccc}
\hline Period & $\begin{array}{c}\text { Observ- } \\
\text { ations } \\
\text { (firms) }\end{array}$ & $\begin{array}{c}\text { Median of } \\
\text { Real } \\
\text { K/Output }\end{array}$ & $\begin{array}{c}\text { Median of } \\
\text { Real } \\
\text { K/Capital }\end{array}$ & $\begin{array}{c}\text { Median } \\
\text { growth of } \\
\text { R\&D* }\end{array}$ \\
\hline $1974-1978$ & $3045(609)$ & 0.112 & 0.212 & $3.0 \%$ \\
$1979-1983$ & $2990(598)$ & 0.124 & 0.238 & $5.1 \%$ \\
$1984-1988$ & $2535(507)$ & 0.171 & 0.310 & $6.9 \%$ \\
$1989-1993$ & $2915(583)$ & 0.195 & 0.350 & $6.8 \%$ \\
$1994-1998$ & $2735(547)$ & 0.195 & 0.327 & $8.1 \%$ \\
$1999-2003$ & $2530(506)$ & 0.194 & 0.250 & $5.6 \%$ \\
All years & $16750(1521)$ & 0.139 & 0.272 & $6.0 \%$ \\
\hline
\end{tabular}

\begin{tabular}{|c|c|c|c|c|c|c|c|c|c|}
\hline Period & $\begin{array}{l}\text { LAD coeff. } \\
\text { for } \log \\
\text { Capital }\end{array}$ & $\begin{array}{c}\text { Standard } \\
\text { error }\end{array}$ & $\begin{array}{c}\text { LAD } \\
\text { coefficient } \\
\text { for } \log \mathrm{K}\end{array}$ & $\begin{array}{l}\text { Standard } \\
\text { error }\end{array}$ & $\begin{array}{c}\text { Ratio of } \\
\text { LAD } \\
\text { coefficients }\end{array}$ & $\begin{array}{c}\text { Standard } \\
\text { error }\end{array}$ & $\begin{array}{c}\text { Implied cost } \\
\text { of R\&D } \\
\text { capital** }\end{array}$ & $\begin{array}{l}\text { Implied } \\
\text { deprec. } \\
\text { rate*** }\end{array}$ & $\begin{array}{l}\text { Median } \\
\text { standard } \\
\text { error*** }\end{array}$ \\
\hline 1974-1978 & 0.466 & 0.016 & 0.011 & 0.007 & 0.023 & 0.016 & $2.5 \%$ & $-12.0 \%$ & $1.2 \%$ \\
\hline $1979-1983$ & 0.444 & 0.017 & 0.042 & 0.010 & 0.095 & 0.024 & $10.9 \%$ & $-17.8 \%$ & $4.5 \%$ \\
\hline 1984-1988 & 0.398 & 0.017 & 0.043 & 0.008 & 0.109 & 0.023 & $7.6 \%$ & $-12.7 \%$ & $1.1 \%$ \\
\hline $1989-1993$ & 0.369 & 0.013 & 0.086 & 0.009 & 0.232 & 0.028 & $13.8 \%$ & $-8.5 \%$ & $0.6 \%$ \\
\hline 1994-1998 & 0.376 & 0.013 & 0.123 & 0.009 & 0.328 & 0.030 & $18.5 \%$ & $-8.3 \%$ & $0.4 \%$ \\
\hline $1999-2003$ & 0.328 & 0.016 & 0.133 & 0.011 & 0.406 & 0.048 & $26.6 \%$ & $-4.7 \%$ & $0.4 \%$ \\
\hline All years & 0.395 & 0.001 & 0.075 & 0.003 & 0.191 & 0.011 & $12.5 \%$ & $-6.6 \%$ & $0.2 \%$ \\
\hline Period & \multicolumn{9}{|c|}{ With correction for double counting of $R \& D$} \\
\hline $1974-1978$ & 0.455 & 0.015 & 0.050 & 0.010 & 0.111 & 0.023 & $11.9 \%$ & $-11.1 \%$ & $2.3 \%$ \\
\hline $1979-1983$ & 0.415 & 0.019 & 0.089 & 0.011 & 0.215 & 0.032 & $24.8 \%$ & $-1.4 \%$ & $2.4 \%$ \\
\hline 1984-1988 & 0.384 & 0.014 & 0.092 & 0.011 & 0.240 & 0.032 & $16.8 \%$ & $-9.7 \%$ & $1.1 \%$ \\
\hline $1989-1993$ & 0.364 & 0.014 & 0.132 & 0.013 & 0.363 & 0.043 & $21.7 \%$ & $-6.5 \%$ & $0.6 \%$ \\
\hline 1994-1998 & 0.373 & 0.014 & 0.151 & 0.011 & 0.405 & 0.035 & $22.9 \%$ & $-7.8 \%$ & $0.4 \%$ \\
\hline 1999-2003 & 0.333 & 0.017 & 0.186 & 0.014 & 0.559 & 0.060 & $36.7 \%$ & $-4.1 \%$ & $0.3 \%$ \\
\hline All years & 0.394 & 0.007 & 0.102 & 0.005 & 0.258 & 0.014 & $19.7 \%$ & $-6.0 \%$ & $0.4 \%$ \\
\hline
\end{tabular}

LAD estimates of log deflated sales on log employees, log capital stock, log R\&D stock K,14 industry dummies, and year dummies. The estimated coefficients and bootstrap standard errors of $\log$ R\&D stock, log capital and their ratio are shown.

*The average growth of R\&D between 1970 (or the year of entry) and the beginning of the year in question, for the median firm.

**The median of the ratio of the coefficients to the R\&D-capital ratio times the cost of ordinary capital.

$* * *$ The median and median standard error of the estimated depreciation rate for R\&D capital, computed as described in the text. 
Table 3

Production function estimates by sector

\begin{tabular}{|c|c|c|c|c|c|c|}
\hline Period & $\begin{array}{l}\begin{array}{c}\text { Chemicals \& } \\
\text { chem-based }\end{array} \\
\end{array}$ & $\begin{array}{c}\text { Drugs \& med } \\
\text { instruments }\end{array}$ & Electrical & $\begin{array}{c}\text { Computers \& } \\
\text { instruments }\end{array}$ & $\begin{array}{c}\text { Metals \& } \\
\text { machinery }\end{array}$ & Miscellaneous \\
\hline & \multicolumn{6}{|c|}{ Number of observations } \\
\hline 1974-1978 & 400 & 310 & 290 & 695 & 860 & 490 \\
\hline $1979-1983$ & 350 & 325 & 290 & 820 & 750 & 455 \\
\hline 1984-1988 & 290 & 305 & 230 & 760 & 605 & 345 \\
\hline 1989-1993 & 310 & 415 & 185 & 1045 & 610 & 350 \\
\hline 1994-1998 & 250 & 455 & 205 & 920 & 615 & 290 \\
\hline 1999-2003 & 235 & 470 & 200 & 750 & 570 & 305 \\
\hline \multirow[t]{2}{*}{ All years } & 1835 & 2280 & 1400 & 4990 & 4010 & 2235 \\
\hline & \multicolumn{6}{|c|}{ Median of Real K/Capital ratio } \\
\hline 1974-1978 & 0.201 & 0.350 & 0.238 & 0.437 & 0.148 & 0.101 \\
\hline 1979-1983 & 0.192 & 0.365 & 0.260 & 0.494 & 0.162 & 0.109 \\
\hline 1984-1988 & 0.250 & 0.464 & 0.318 & 0.565 & 0.185 & 0.119 \\
\hline 1989-1993 & 0.239 & 0.488 & 0.375 & 0.694 & 0.192 & 0.116 \\
\hline 1994-1998 & 0.185 & 0.450 & 0.263 & 0.686 & 0.190 & 0.131 \\
\hline $1999-2003$ & 0.165 & 0.390 & 0.224 & 0.568 & 0.150 & 0.134 \\
\hline All years & 0.200 & 0.403 & 0.271 & 0.566 & 0.166 & 0.114 \\
\hline
\end{tabular}

\begin{tabular}{ccccccc}
\hline \multicolumn{7}{c}{ Ratio of Log K to Log C coefficient (standard error)* } \\
\hline $1974-1978$ & $0.28(0.07)$ & $0.28(0.09)$ & $0.09(0.05)$ & $0.18(0.05)$ & $0.25(0.12)$ & $0.12(0.08)$ \\
$1979-1983$ & $0.35(0.10)$ & $0.27(0.05)$ & $-0.01(0.09)$ & $0.41(0.12)$ & $0.29(0.07)$ & $0.37(0.12)$ \\
$1984-1988$ & $0.20(0.06)$ & $0.17(0.10)$ & $0.57(0.27)$ & $0.70(0.13)$ & $0.19(0.10)$ & $0.35(0.18)$ \\
$1989-1993$ & $0.26(0.11)$ & $0.25(0.11)$ & $1.41(0.63)$ & $0.76(0.20)$ & $0.63(0.22)$ & $0.69(0.22)$ \\
$1994-1998$ & $0.79(0.26)$ & $0.49(0.12)$ & $0.34(0.07)$ & $0.81(0.16)$ & $0.36(0.08)$ & $0.77(0.15)$ \\
$1999-2003$ & $0.55(0.18)$ & $0.33(0.08)$ & $1.34(0.58)$ & $1.84(0.29)$ & $0.46(0.07)$ & $0.52(0.09)$ \\
All years & $0.29(0.04)$ & $0.13(0.03)$ & $0.28(0.04)$ & $0.67(0.07)$ & $0.23(0.03)$ & $0.29(0.05)$ \\
\hline \multicolumn{7}{c}{ Implied cost of R\&D capital } \\
\hline $1974-1978$ & $31.6 \%$ & $18.1 \%$ & $8.4 \%$ & $9.1 \%$ & $37.6 \%$ & $26.2 \%$ \\
$1979-1983$ & $49.5 \%$ & $20.4 \%$ & $-0.7 \%$ & $22.9 \%$ & $48.9 \%$ & $94.0 \%$ \\
$1984-1988$ & $17.0 \%$ & $8.1 \%$ & $38.7 \%$ & $26.7 \%$ & $22.8 \%$ & $62.7 \%$ \\
$1989-1993$ & $22.7 \%$ & $10.5 \%$ & $78.6 \%$ & $23.0 \%$ & $68.1 \%$ & $123.5 \%$ \\
$1994-1998$ & $79.2 \%$ & $20.1 \%$ & $24.2 \%$ & $21.7 \%$ & $34.9 \%$ & $108.7 \%$ \\
$1999-2003$ & $55.1 \%$ & $13.9 \%$ & $98.0 \%$ & $53.1 \%$ & $50.9 \%$ & $63.2 \%$ \\
All years & $31.1 \%$ & $6.2 \%$ & $22.5 \%$ & $24.6 \%$ & $29.9 \%$ & $55.7 \%$ \\
\hline \multicolumn{7}{c}{ Estimated R\&D depreciation rate in per cent (median standard error)** } \\
\hline $1974-1978$ & $1.9(2.8)$ & $-9.0(6.2)$ & $-12.5(6.8)$ & $-12.3(2.8)$ & $2.7(1.7)$ & $3.7(8.3)$ \\
$1979-1983$ & $1.0(2.1)$ & $-3.6(6.9)$ & $-14.9(6.4)$ & $-2.0(7.5)$ & $0.6(1.8)$ & $-1.3(0.9)$ \\
$1984-1988$ & $-11.3(4.3)$ & $-13.7(3.3)$ & $-3.5(3.7)$ & $-6.4(3.0)$ & $-4.2(7.1)$ & $-4.2(1.5)$ \\
$1989-1993$ & $-6.1(3.5)$ & $-8.9(2.8)$ & $-4.2(0.8)$ & $-6.0(2.6)$ & $-3.2(0.7)$ & $-5.2(0.3)$ \\
$1994-1998$ & $-4.7(0.3)$ & $-8.4(1.7)$ & $-9.4(2.1)$ & $-7.6(1.5)$ & $-5.6(1.1)$ & $-7.2(0.1)$ \\
$1999-2003$ & $-1.2(0.9)$ & $-6.8(1.0)$ & $-4.3(0.4)$ & $-5.3(0.6)$ & $-3.7(0.3)$ & $-2.9(0.3)$ \\
All years & $-2.3(1.6)$ & $-10.9(0.7)$ & $-3.0(2.1)$ & $-5.0(1.0)$ & $-1.8(1.2)$ & $-2.3(0.6)$ \\
\hline
\end{tabular}

LAD estimates of log deflated sales on log employees, log capital stock, log R\&D stock K, and industry and year dummies. *The ratio of the estimated coefficients of $\log R \& D$ stock and log capital and its standard error are shown.

**The median and median standard error of the estimated depreciation rate for R\&D capital, computed using equation (9). 


\section{Table 4}

\section{Market value equation estimates}

\begin{tabular}{|c|c|c|c|c|}
\hline Period & Observations & $\begin{array}{c}\text { Median K/A } \\
\text { (nominal) } \\
\left(p_{K} K / p_{A} A\right)\end{array}$ & $\begin{array}{l}\text { Interquartile } \\
\text { range for } \\
\text { nominal K/A }\end{array}$ & $\begin{array}{l}\text { Median real } \\
\text { growth of } \\
\operatorname{R\& D}\left(g_{R}\right)\end{array}$ \\
\hline 1974-1978 & 3045 & 0.176 & 0.233 & $3.0 \%$ \\
\hline 1979-1983 & 2990 & 0.211 & 0.290 & $5.3 \%$ \\
\hline 1984-1988 & 2535 & 0.285 & 0.404 & $6.9 \%$ \\
\hline 1989-1993 & 2915 & 0.349 & 0.561 & $6.7 \%$ \\
\hline 1994-1998 & 2735 & 0.335 & 0.606 & $8.1 \%$ \\
\hline 1999-2003 & 2530 & 0.308 & 0.571 & $4.7 \%$ \\
\hline All years & 16750 & 0.261 & 0.409 & $5.9 \%$ \\
\hline \multicolumn{3}{|c|}{$\mathrm{K} / \mathrm{A}$} & \multicolumn{2}{|c|}{ Implied depreciation rate $* * *$} \\
\hline \multirow[t]{2}{*}{ Period } & Coefficient & Std. err. & Median & Median s.e. \\
\hline & \multicolumn{4}{|c|}{ Ordinary least squares* } \\
\hline 1974-1978 & 0.352 & 0.053 & $34.3 \%$ & $3.6 \%$ \\
\hline $1979-1983$ & 0.416 & 0.046 & $31.8 \%$ & $2.7 \%$ \\
\hline 1984-1988 & 0.287 & 0.032 & $42.1 \%$ & $3.0 \%$ \\
\hline 1989-1993 & 0.239 & 0.024 & $46.9 \%$ & $2.6 \%$ \\
\hline 1994-1998 & 0.302 & 0.028 & $41.5 \%$ & $2.5 \%$ \\
\hline 1999-2003 & 0.366 & 0.026 & $34.4 \%$ & $1.7 \%$ \\
\hline \multirow[t]{2}{*}{ All years } & 0.297 & 0.013 & $40.6 \%$ & $1.2 \%$ \\
\hline & \multicolumn{4}{|c|}{ Least absolute deviations** } \\
\hline 1974-1978 & 0.390 & 0.049 & $31.9 \%$ & $2.6 \%$ \\
\hline $1979-1983$ & 0.466 & 0.052 & $29.0 \%$ & $2.5 \%$ \\
\hline 1984-1988 & 0.271 & 0.034 & $43.6 \%$ & $4.0 \%$ \\
\hline 1989-1993 & 0.274 & 0.033 & $43.2 \%$ & $3.3 \%$ \\
\hline 1994-1998 & 0.316 & 0.043 & $40.3 \%$ & $3.2 \%$ \\
\hline 1999-2003 & 0.404 & 0.033 & $32.1 \%$ & $1.9 \%$ \\
\hline \multirow[t]{2}{*}{ All years } & 0.297 & 0.017 & $40.6 \%$ & $1.4 \%$ \\
\hline & \multicolumn{4}{|c|}{ Nonlinear estimation* } \\
\hline 1974-1978 & 0.526 & 0.079 & $25.4 \%$ & $3.1 \%$ \\
\hline 1979-1983 & 0.595 & 0.071 & $23.6 \%$ & $2.5 \%$ \\
\hline 1984-1988 & 0.385 & 0.050 & $34.5 \%$ & $3.3 \%$ \\
\hline 1989-1993 & 0.382 & 0.042 & $34.5 \%$ & $2.8 \%$ \\
\hline 1994-1998 & 0.551 & 0.059 & $26.2 \%$ & $2.5 \%$ \\
\hline 1999-2003 & 0.794 & 0.078 & $17.9 \%$ & $1.7 \%$ \\
\hline All years & 0.503 & 0.025 & $27.5 \%$ & $1.2 \%$ \\
\hline
\end{tabular}

Year dummies and 14 industry dummies are included in the equations.

*Robust standard errors are shown for these two estimators.

**Standard errors computed via the bootstrap with 200 replications.

***The R\&D depreciation rate computed using the estimated coefficient and each firm's R\&D growth rate under the assumption that the true K/A coefficient is one. The median and the median standard error are shown. 
Table 5

Market value equation estimates by sector

\begin{tabular}{|c|c|c|c|c|c|c|}
\hline Period & Chemicals & $\begin{array}{c}\text { Drugs \& med } \\
\text { instruments }\end{array}$ & Electrical & $\begin{array}{c}\text { Computers \& } \\
\text { instruments }\end{array}$ & $\begin{array}{c}\text { Metals \& } \\
\text { machinery }\end{array}$ & Miscellaneous \\
\hline & \multicolumn{6}{|c|}{ Number of observations } \\
\hline 1974-1978 & 400 & 310 & 290 & 695 & 860 & 490 \\
\hline 1979-1983 & 350 & 325 & 290 & 820 & 750 & 455 \\
\hline 1984-1988 & 290 & 305 & 230 & 760 & 605 & 345 \\
\hline 1989-1993 & 310 & 415 & 185 & 1045 & 610 & 350 \\
\hline 1994-1998 & 250 & 455 & 205 & 920 & 615 & 290 \\
\hline 1999-2003 & 235 & 470 & 200 & 750 & 570 & 305 \\
\hline \multirow[t]{2}{*}{ All years } & 1835 & 2280 & 1400 & 4990 & 4010 & 2235 \\
\hline & \multicolumn{6}{|c|}{ Median of Nominal $K /$ tangible assets ratio $\left(p_{K} K / p_{A} A\right)$} \\
\hline $1974-1978$ & 0.167 & 0.281 & 0.208 & 0.362 & 0.122 & 0.082 \\
\hline 1979-1983 & 0.167 & 0.315 & 0.229 & 0.428 & 0.140 & 0.094 \\
\hline 1984-1988 & 0.231 & 0.429 & 0.294 & 0.532 & 0.168 & 0.109 \\
\hline $1989-1993$ & 0.233 & 0.486 & 0.354 & 0.706 & 0.188 & 0.115 \\
\hline 1994-1998 & 0.193 & 0.472 & 0.274 & 0.706 & 0.195 & 0.137 \\
\hline 1999-2003 & 0.198 & 0.473 & 0.274 & 0.706 & 0.181 & 0.163 \\
\hline \multirow[t]{2}{*}{ All years } & 0.192 & 0.394 & 0.264 & 0.547 & 0.155 & 0.109 \\
\hline & \multicolumn{6}{|c|}{ Median of real $R \& D$ growth rate $\left(g_{R}\right)$} \\
\hline $1974-1978$ & $2.7 \%$ & $4.4 \%$ & $2.2 \%$ & $4.0 \%$ & $2.6 \%$ & $2.5 \%$ \\
\hline 1979-1983 & $4.7 \%$ & $6.1 \%$ & $5.2 \%$ & $7.4 \%$ & $4.6 \%$ & $4.6 \%$ \\
\hline 1984-1988 & $5.9 \%$ & $7.7 \%$ & $6.8 \%$ & $9.1 \%$ & $5.8 \%$ & $6.4 \%$ \\
\hline 1989-1993 & $5.6 \%$ & $8.4 \%$ & $6.0 \%$ & $8.7 \%$ & $5.0 \%$ & $5.9 \%$ \\
\hline 1994-1998 & $6.2 \%$ & $9.5 \%$ & $8.1 \%$ & $9.4 \%$ & $6.8 \%$ & $7.6 \%$ \\
\hline 1999-2003 & $2.9 \%$ & $5.5 \%$ & $3.9 \%$ & $6.3 \%$ & $4.2 \%$ & $3.7 \%$ \\
\hline \multirow[t]{2}{*}{ All years } & $4.9 \%$ & $7.1 \%$ & $5.2 \%$ & $7.9 \%$ & $4.9 \%$ & $5.0 \%$ \\
\hline & \multicolumn{6}{|c|}{ K/A coefficient $(\text { s.e. })^{*}$} \\
\hline 1974-1978 & $0.63(0.26)$ & $1.69(0.40)$ & $0.35(0.23)$ & $0.60(0.12)$ & $-0.11(0.07)$ & $0.46(0.31)$ \\
\hline $1979-1983$ & $1.21(0.23)$ & $0.92(0.23)$ & $0.81(0.25)$ & $0.34(0.09)$ & $0.78(0.16)$ & $0.44(0.25)$ \\
\hline 1984-1988 & $1.23(0.19)$ & $1.58(0.36)$ & $0.69(0.14)$ & $0.24(0.07)$ & $0.15(0.06)$ & $0.02(0.08)$ \\
\hline 1989-1993 & $0.45(0.17)$ & $0.76(0.17)$ & $0.03(0.09)$ & $0.39(0.05)$ & $0.11(0.06)$ & $0.32(0.16)$ \\
\hline 1994-1998 & $0.70(0.24)$ & $0.83(0.16)$ & $0.33(0.12)$ & $0.45(0.08)$ & $0.47(0.13)$ & $1.84(0.36)$ \\
\hline 1999-2003 & $0.45(0.17)$ & $0.87(0.18)$ & $0.33(0.15)$ & $0.71(0.11)$ & $0.97(0.19)$ & $2.65(0.46)$ \\
\hline \multirow[t]{2}{*}{ All years } & $0.73(0.09)$ & $0.95(0.07)$ & $0.35(0.07)$ & $0.46(0.04)$ & $0.42(0.05)$ & $0.69(0.13)$ \\
\hline & \multicolumn{6}{|c|}{ Median estimated R\&D depreciation rate in per cent (median standard error)** } \\
\hline $1974-1978$ & $21.6(7.6)$ & $7.4(2.5)$ & $34.0(15.0)$ & $23.1(4.1)$ & $>100$ & $28.0(14.0)$ \\
\hline $1979-1983$ & $11.3(2.5)$ & $15.5(4.3)$ & $17.6(5.4)$ & $38.0(6.9)$ & $18.1(3.6)$ & $30.1(13.4)$ \\
\hline 1984-1988 & $10.9(2.2)$ & $7.1(2.9)$ & $20.9(4.2)$ & $48.5(7.5)$ & $57.8(9.5)$ & $90.2(29.0)$ \\
\hline 1989-1993 & $29.8(8.7)$ & $19.2(4.7)$ & $88.4(31.7)$ & $35.4(3.6)$ & $65.3(13.4)$ & $39.0(13.5)$ \\
\hline 1994-1998 & $20.6(6.9)$ & $17.6(4.0)$ & $39.4(9.9)$ & $31.5(4.5)$ & $29.5(6.4)$ & $5.3(2.2)$ \\
\hline 1999-2003 & $28.6(8.4)$ & $16.3(3.6)$ & $37.2(11.5)$ & $20.4(3.2)$ & $14.5(3.0)$ & $3.9(1.2)$ \\
\hline All years & $19.4(2.2)$ & $14.9(1.7)$ & $35.7(4.7)$ & $30.6(1.9)$ & $31.5(3.1)$ & $20.7(3.6)$ \\
\hline
\end{tabular}

*Nonlinear least squares estimates with dependent variable log Q, robust standard errors. Industry and year dummies included.

**The depreciation rate computed under the assumption that the true K/A coefficient is equal to one. 


\section{Appendix A: Choosing the Sample of Firms}

This appendix describes the creation of the sample. The starting point was 104,000 Compustat observations on about 9000 firms between 1970 and 2004 in SIC 2000-3999 inclusive. Observations with sales, employment, market value, or capital stock missing or R\&D missing or zero were removed, as were firms (or parts of firms) that had 3 or fewer observations in successive years. ${ }^{15}$ Foreign firms (either recorded as located outside the US by Compustat or containing -ADR, NV, PLC, or LTD in the name) were also removed.

As is well known to anyone working with data from this source, in many cases there are large changes in one or more variables from year to year, in some cases due to mergers and divestitures and sometimes simply due to incorrectly entered data. Because of the size of the file it is not feasible to clean the data manually, so another approach was necessary. First, ratios and growth rates of key variables were checked for validity using rules given in Table A1. Second, where there were substantial breaks in a firm's series, a new firm was created after the break. This procedure is justified by the fact that where large changes occur it is not reasonable to think of the firm as being the same entity over time. Third, most of the estimates have been computed using a least absolute deviations estimator rather than ordinary least squares, to reduce the sensitivity to outliers.

The above procedure left about 29,000 observations in an unbalanced panel from 1973 to 2003. From this, 6 balanced panels with 5 years of data each ( 6 years including lagged capital) were chosen for a total of 16,750 observations. Some information on the selection is given in Table A2. Although the selection is fairly severe, Figure A1 shows that there is still significant coverage of the total R\&D in the economy. The unbalanced sample includes 98 per cent of the R\&D in the manufacturing sector master file until 1993; coverage then drops to 90 per cent in the final ten years. The partially balanced panels display a similar but somewhat lower pattern. The decline in the later years appears to be caused by a number of new entrants whose data series are not long enough to be included in the sample.

Table A3 gives the distribution of firms and observations by two-digit industry (and a few three-digit industries) and the allocation of the industries to the six main technology sectors that are used in Tables 3 and 6.

\footnotetext{
${ }^{15}$ Requiring good data on sales, employment and q removed about one third of the observations, because Compustat includes firms that file with the U.S. Securities and Exchange Commission for a number of reasons; many of these firms are not publicly traded but have some outstanding debt whose ownership is dispersed.
} 


\section{Table A1}

\section{Selecting the sample}

\begin{tabular}{|ll|}
\hline Variable & Restriction for sample \\
\hline Employment & Greater than 100 employees \\
\hline Modified Tobin's q & Between 0.1 and 20 \\
\hline Modified Tobin's q & Absolute value of growth $<500 \%$ \\
\hline Intangibles-capital stock ratio & Current and lagged $<100 \%$ \\
\hline K stock-capital stock ratio & Between 1\% and 500\% \\
\hline R\&D-capital stock ratio & Between $0.1 \%$ and $200 \%$ \\
\hline R\&D-sales ratio & Between $0.1 \%$ and $100 \%$ \\
\hline K-sales ratio & Between $1 \%$ and 500\% \\
\hline Capital-sales ratio & Between $1 \%$ and 500\% \\
\hline Capital-employment ratio & Between $\$ 1000$ and $\$ 2 \mathrm{M}$ \\
\hline Growth in sales & Absolute value $<150 \%$ \\
\hline Growth in employment & Absolute value $<100 \%$ \\
\hline Growth in capital stock & Absolute value $<100 \%$ \\
\hline Growth in K stock & Absolute value $<100 \%$ \\
\hline Growth in R\&D & Absolute value $<150 \%$ \\
\hline Sales-employment ratio & Between $\$ 5000$ and $\$ 2 \mathrm{M}$ \\
\hline K stock-employment ratio & Between $\$ 500$ and $\$ 2 \mathrm{M}$ \\
\hline
\end{tabular}

Figure A1

$R \& D$ coverage of sample

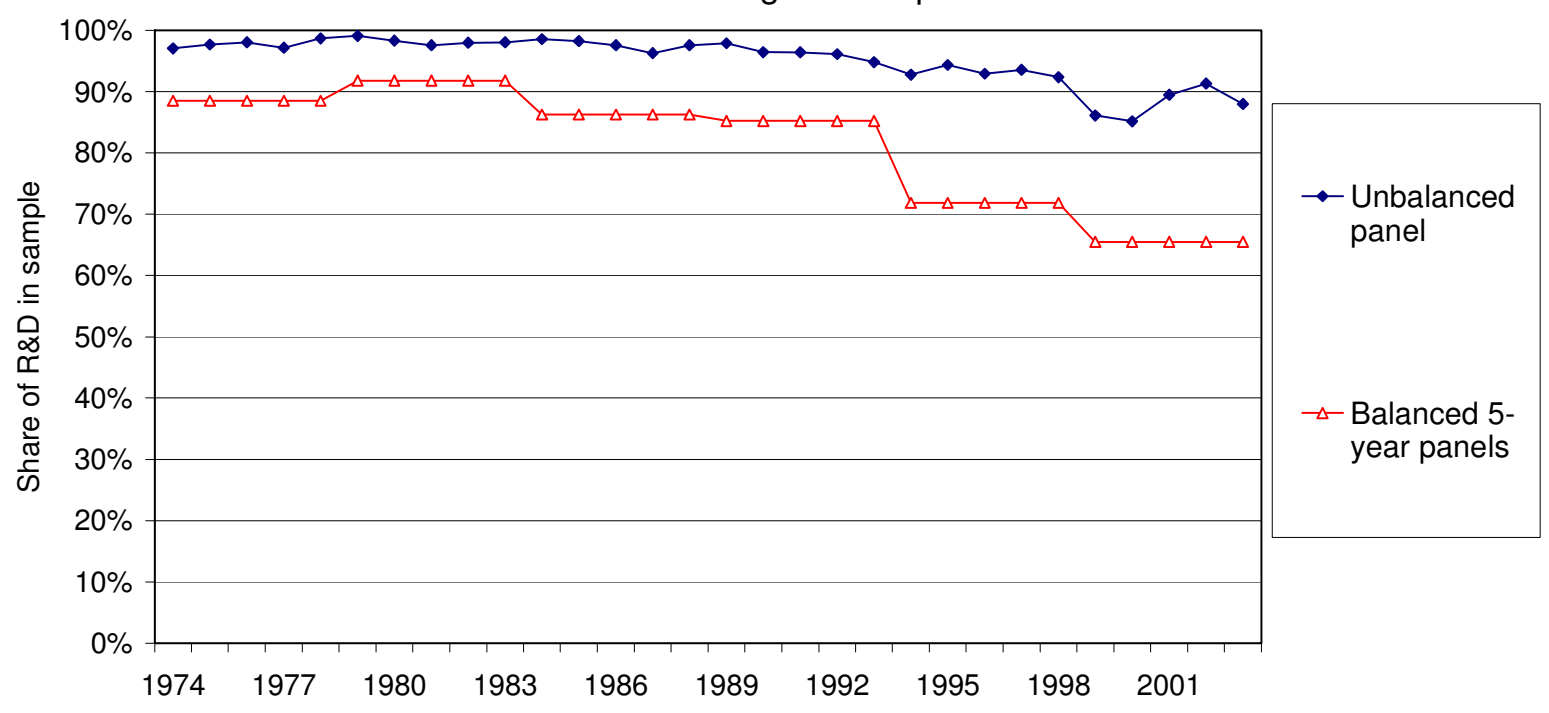


Table A2

Choosing the sample of firms from Compustat*

\begin{tabular}{|c|c|c|c|c|c|c|c|c|}
\hline \multirow[b]{2}{*}{ Period } & \multirow{2}{*}{$\begin{array}{c}\text { Raw data } \\
\text { (manu- } \\
\text { facturing) } \\
\text { Observations } \\
\end{array}$} & \multicolumn{2}{|c|}{$\begin{array}{l}\text { Domestic Manufacturing } \\
\text { Firms with sales, } \\
\text { employment and q }\end{array}$} & \multirow{2}{*}{$\begin{array}{l}\text { Unbalanced } \\
\text { R\&D sample } \\
\text { Observations } \\
\end{array}$} & \multicolumn{2}{|c|}{$\begin{array}{c}\text { 5-year } \\
\text { balanced samples with } \\
\text { R\&D }\end{array}$} & \multicolumn{2}{|c|}{ Sample share } \\
\hline & & Observations & Firms & & Observations & Firms & Observations & Firms \\
\hline 1974-1978 & 14971 & 9001 & 2188 & 4822 & 3045 & 609 & $34 \%$ & $28 \%$ \\
\hline $1979-1983$ & 14540 & 9414 & 2425 & 4662 & 2990 & 598 & $32 \%$ & $25 \%$ \\
\hline 1984-1988 & 16285 & 9792 & 2660 & 4776 & 2535 & 507 & $26 \%$ & $19 \%$ \\
\hline $1989-1993$ & 16574 & 9873 & 2654 & 4696 & 2915 & 583 & $30 \%$ & $22 \%$ \\
\hline 1994-1998 & 21272 & 12142 & 3113 & 5383 & 2735 & 547 & $23 \%$ & $18 \%$ \\
\hline $1999-2003$ & 21024 & 10418 & 2644 & 4598 & 2530 & 506 & $24 \%$ & $19 \%$ \\
\hline Total & 104666 & 60640 & 6189 & 28937 & 16750 & 1350 & $28 \%$ & $22 \%$ \\
\hline
\end{tabular}

*The source is the Compustat annual industrial file as of 2005, all years, SIC $=2000$ to 3999

Table A3

Distribution of the Sample by Industry

\begin{tabular}{|c|c|c|c|}
\hline Sector & Two-digit industry & Firms & Observations \\
\hline \multirow[t]{3}{*}{$\overline{\text { Chemicals \& chemical-based }}$} & 28 Chemicals ex pharmaceuticals & 82 & 1,095 \\
\hline & 29 Oil & 19 & 255 \\
\hline & 30 Rubber \& plastics & 47 & 485 \\
\hline \multirow{2}{*}{$\begin{array}{l}\text { Pharmaceuticals \& medical } \\
\text { instruments }\end{array}$} & & & \\
\hline & $\begin{array}{l}283 \text { Pharmaceuticals \& biotechnology } \\
384 \text { Medical \& dental instruments }\end{array}$ & $\begin{array}{l}106 \\
100\end{array}$ & $\begin{array}{r}1,395 \\
885\end{array}$ \\
\hline \multirow[t]{2}{*}{ Electrical equipment } & 36 Electrical equipment & 88 & 940 \\
\hline & 37 Aircraft & 34 & 460 \\
\hline \multirow{4}{*}{$\begin{array}{l}\text { Computers, communnication } \\
\text { eq., \& scientific instruments }\end{array}$} & & & \\
\hline & 357 Office machinery & 110 & 1,035 \\
\hline & 367 Commmunication equipment & 218 & 2,245 \\
\hline & 38 Scientific instruments & 148 & 1,710 \\
\hline \multirow[t]{4}{*}{ Metals \& machinery } & 33 Primary metals & 42 & 465 \\
\hline & 34 Fabricated metals & 79 & 870 \\
\hline & 35 Machinery & 185 & 1,960 \\
\hline & 37 Autos \& other transport & 57 & 715 \\
\hline \multirow[t]{11}{*}{ Miscellaneous } & 20 Food \& kindred products & 32 & 355 \\
\hline & 21 Tobacco & 3 & 25 \\
\hline & 22 Textile mill products & 27 & 215 \\
\hline & 23 Apparel \& other textile products & 6 & 35 \\
\hline & 24 Lumber \& wood products & 7 & 65 \\
\hline & 25 Furniture $\&$ fixtures & 25 & 360 \\
\hline & 26 Paper \& allied products & 35 & 400 \\
\hline & 27 Printing \& publishing & 10 & 105 \\
\hline & 31 Leather \& allied products & 6 & 55 \\
\hline & 32 Stone, clay, \& glass & 23 & 270 \\
\hline & 39 Miscellaneous NEC & 32 & 350 \\
\hline Totals & All manufacturing & 1521 & 16,750 \\
\hline
\end{tabular}




\section{Appendix B: Hayashi-Inoue Model Applied to R\&D Assets}

This appendix presents a theoretical $Q$ model of investment with two or more capital assets that is due to Hayashi and Inoue (1991), applied to the case of R\&D assets. The $Q$ model, originally due to Tobin, defines $Q$ as the ratio of the market value $V$ of a (unique) asset to its replacement cost $A$. The theory had the following implications:

- $\mathrm{Q}>1=>$ the firm or other similar firms should invest to create more of the asset and drive its value down to replacement cost.

- $\mathrm{Q}<1=>$ the firm should shrink or disinvest to reduce the amount of the asset until its value rises to its replacement cost.

- $\mathrm{Q}=1$ in equilibrium.

If the market value of a firm is equal to the value of its dynamic program of investment, the ideal theoretical specification would be derived by modeling investment in tangible and intangible (knowledge) assets under uncertainty using a dynamic program for the firm. From this we could obtain a value function of the assets (state variables) of the firm and use it as a basis for estimation.

Under the assumption that the asset being modeled is a firm and that its Q is derived from the firm's dynamic program, Hayashi (1982) gave conditions under which marginal Q $(d V / d A)$ is equal to average (V/A). Hayashi and Inoue (1991) and Wildasin (1984) developed the theory with more than one asset (capital). In this appendix I use Hayashi and Inoue's model of a firm with multiple capitals to derive the value function for a firm with two capitals, tangible and intangible, and discuss the interpretation of the estimating model in the light of the theory.

The Hayashi and Inoue (HI) model is based on the idea that the firm's problem is weakly separable into two stages: the top stage allocates a capital aggregate across time, and the bottom stage chooses levels of the individual capitals that make up the aggregate under cost minimization. Aggregating capital in this way allows for a familiar Tobin's $q$ interpretation where the capital aggregate plays the role that the single capital asset plays in the traditional model. In particular, the result that marginal $q$ is equal to average $q$ can be obtained under the assumption of constant returns to scale in the profit, aggregate, and adjustment cost functions. 
In my version of the model the two capitals will be denoted by $A_{t}$ (tangible) and $K_{t}$ (intangible), the corresponding investments by $I_{t}$ and $R_{t}$, their prices by $p_{t}^{I}$ and $p_{t}^{R}$ respectively, and their depreciation rates by $\delta_{I}$ and $\delta_{R}$. The capital aggregate is denoted $\varphi\left(A_{t}, K_{t}\right)$ and the (stochastic) output price by $p_{t}$. In contrast to $\mathrm{HI}$, I assume a single constant discount rate $\beta$; this can easily be generalized. I also ignore tax considerations for the moment. Given this notation, the firm's profit maximizing problem is given by the following expression: ${ }^{16}$

$$
\begin{aligned}
\max V_{0} & =E_{0} \sum_{t=0}^{\infty} \beta^{t}\left[\Pi\left(A_{t}, K_{t}, A_{t+1}, K_{t+1} ; p_{t}\right)-p_{t}^{I} I_{t}-p_{t}^{R} R_{t}\right] \\
\text { s.t. } A_{t+1} & =\left(1-\delta_{I}\right) A_{t}+I_{t} \\
K_{t+1} & =\left(1-\delta_{R}\right) K_{t}+R_{t}
\end{aligned}
$$

where the profit function $\pi($.$) incorporates adjustment cost functions for the two capitals and all the$ variable factors are optimized out period by period. The state variables for this problem are $A_{t}$ and $K_{t}$, along with the exogenous processes for the three prices, which vary only over time and possibly industry, and the control variables are the two investment choices. The prices are assumed to be driven by a single first order Markov process $\left(s_{t}, t=0,1, \ldots\right)$.

To obtain the value function used for estimation, it is convenient to substitute in the accumulation constraints, eliminating $I_{t}$ and $R_{t}$ from the problem. The new control variables will be one plus net capital growth (that is, $A_{t+1} / A_{t}$ and $\mathrm{K}_{t+1} / K_{t}$ ), rather than gross investments. After some manipulation, we obtain

$$
\begin{aligned}
V_{0} & =p_{0}^{I}\left(1-\delta_{I}\right) A_{0}+p_{0}^{R}\left(1-\delta_{R}\right) K_{0}+W_{0} \\
\text { with } W_{0} & =E_{0} \sum_{t=0}^{\infty} \beta^{t}\left[\Pi\left(A_{t}, K_{t}, A_{t+1}, K_{t+1} ; p_{t}\right)-c_{t}^{A} A_{t+1}-c_{t}^{K} K_{t+1}\right]
\end{aligned}
$$

where the costs of capital $c_{t}$ are given by equation (7), suitably modified to incorporate expectations:

$$
\begin{aligned}
c_{t}^{A} & =p_{t}^{I}-E_{t}\left[\beta\left(1-\delta_{I}\right) p_{t+1}^{I}\right] \\
c_{t}^{K} & =p_{t}^{R}-E_{t}\left[\beta\left(1-\delta_{R}\right) p_{t+1}^{R}\right]
\end{aligned}
$$

\footnotetext{
${ }^{16}$ Note that the notation is slightly different from that used by Hayashi and Inoue (1991), in that I have used $V$ for the total value of the firm and $W$ for the value of its supranormal rents, whereas $\mathrm{HI}$ used $W$ for the value and $V$ for the rents. The notation used here is more consistent with the previous literature on estimating the market value equation.
} 
The first two terms in the value function describe the current state of the firm, and are not under its control at time 0 . The last term $\left(W_{0}\right)$ represents the rents that are expected to be earned by the firm because of adjustment costs associated with the two capitals. Each term in $W_{0}$ is the profits earned with the current capital levels minus the adjustment costs incurred from moving to next period's capital and the rental cost of that capital. In equilibrium, when capitals are at their optimal level, so that there are no adjustment costs and they simply earn their rental cost, $W_{0}$ will be zero. In that case, only the first two terms of the value function will enter, so that the market value of the two assets will simply be equal to the cost of replacing them at current prices, and aggregate Tobin's $q$ will be unity.

To obtain a tractable form for the rents $W_{0}, \mathrm{HI}$ assume that profits depend only on a capital aggregate, and that both the aggregate and the profit function are linear homogeneous:

$$
\begin{aligned}
\Pi\left(A_{t}, K_{t}, A_{t+1}, K_{t+1} ; p_{t}\right) & =\Pi *\left(\varphi\left(A_{t}, K_{t}\right), \varphi\left(A_{t+1}, K_{t+1}\right) ; p_{t}\right) \\
& =\pi\left(\frac{\varphi\left(A_{t}, K_{t}\right)}{\varphi\left(A_{t+1}, K_{t+1}\right)} ; p_{t}\right) \varphi\left(A_{t+1}, K_{t+1}\right)
\end{aligned}
$$

Using this form of the profit function, they prove that the value of the expected rents $V_{0}$ is a linear function of the capital aggregate:

$$
W_{0}=Q\left(s_{0}\right) \varphi^{*}\left(K_{0} / A_{0}\right) A_{0}
$$

where $Q(s)$ is a function only of the exogenous shocks $s$ and $\varphi^{*}\left(K_{0} / A_{0}\right)$ is the capital aggregator index after constant returns has been imposed. Given this result, the value function for the firm becomes the following:

$$
W_{0}=\left[1+\frac{Q\left(s_{0}\right) \varphi^{*}\left(K_{0} / A_{0}\right)}{p_{0}^{I}\left(1-\delta_{I}\right)}\right] p_{0}^{I}\left(1-\delta_{I}\right) A_{0}+p_{0}^{R}\left(1-\delta_{R}\right) K_{0}
$$

which implies that conventionally measured Tobin's q is related to tangible and intangible assets in the following way:

$$
\begin{aligned}
& q_{0}=\frac{V_{0}}{p_{0}^{I}\left(1-\delta_{I}\right) A_{0}}=1+\frac{Q\left(s_{0}\right)}{p_{0}^{I}\left(1-\delta_{I}\right)} \varphi^{*}\left(K_{0} / A_{0}\right)+\frac{p_{0}^{R}\left(1-\delta_{R}\right) K_{0}}{p_{0}^{I}\left(1-\delta_{I}\right) A_{0}} \\
& \log q_{0}=\log \left[1+\frac{Q\left(s_{0}\right)}{p_{0}^{I}\left(1-\delta_{I}\right)} \varphi^{*}\left(K_{0} / A_{0}\right)+\frac{p_{0}^{R}\left(1-\delta_{R}\right) K_{0}}{p_{0}^{I}\left(1-\delta_{I}\right) A_{0}}\right]
\end{aligned}
$$


This equation states that $q$ is equal to 1 plus a term involving the capital aggregator that captures the possible supranormal rents available to the firm in the future (note that this term contains the index of the exogenous shocks at time 0 ). The final term simply corrects $q$ for the fact that the denominator does not contain the firm's stock of $R \& D$, using the current price of $R \& D$ and the assumed depreciation rate to measure its book value. The contribution of the theory is to demonstrate that under the assumption that the firm can optimize its capital mix in any period in response to the cost of capital, a single index of the shocks will price that mix. Unfortunately, the theory does not tell us how to construct that index.

The equation above suggests the following regression specifications:

$$
\log q_{i t}=\log \alpha_{t}+\log \left[1+\frac{\lambda_{t}}{\alpha_{t}} \varphi^{*}\left(K_{i t} / A_{i t}\right)+\frac{\gamma_{t}}{\alpha_{t}} \frac{p_{i t}^{R}\left(1-\delta_{R}\right) K_{i t}}{p_{i t}^{I}\left(1-\delta_{I}\right) A_{i t}}\right]+\varepsilon_{i t}
$$

where $\gamma$ is included to allow for depreciation rates that change over time or are mismeasured in some way. If a linear specification is desired, we can use:

$$
\log q_{i t}=\log \alpha_{t}+\frac{\lambda_{t}}{\alpha_{t}} \varphi^{*}\left(K_{i t} / A_{i t}\right)+\frac{\gamma_{t}}{\alpha_{t}} \frac{p_{i t}^{R}\left(1-\delta_{R}\right) K_{i t}}{p_{i t}^{I}\left(1-\delta_{I}\right) A_{i t}}+\varepsilon_{i t}
$$

Equation (22) allows depreciation rates and the shocks to vary over time, but not across firms. It may be useful to allow them to vary across industry. Note that I have included a parameter $\alpha_{t}$ to accommodate time-varying depreciation of tangible capital and $\gamma_{t}$ for intangible capital. As further discussed below, the difficulty with these equations empirically is that the capital aggregator and the last term $(K / A)$ will be highly correlated across firms and therefore their coefficients will be unstable.

\section{Computing the capital aggregator}

$\varphi *\left(K_{0} / A_{0}\right)$ is constructed from the capital stocks using standard user cost formulas and a Divisia index, with the costs of capital as the price series, and real capital as the quantity series. In the computations here, I used the costs of capital series already shown in Figure 3. The rate of change of the capital aggregator $\varphi$ is defined by the following equation:

$$
\begin{aligned}
\frac{\Delta \varphi\left(A_{t+1}, K_{t+1}\right)}{\varphi\left(A_{t+1}, K_{t+1}\right)} & =\frac{c_{t}^{A} A_{t+1}}{c_{t}^{A} A_{t+1}+c_{t}^{K} K_{t+1}} \frac{\Delta A_{t+1}}{A_{t+1}}+\frac{c_{t}^{K} K_{t+1}}{c_{t}^{A} A_{t+1}+c_{t}^{K} K_{t+1}} \frac{\Delta K_{t+1}}{K_{t+1}} \\
& =\frac{c_{t}^{A} \Delta A_{t+1}+c_{t}^{K} \Delta K_{t+1}}{c_{t}^{A} A_{t+1}+c_{t}^{K} K_{t+1}}
\end{aligned}
$$


The initial level is computed from the sum of the capitals in the first year (that is, the price is normalized to one).

Once $\varphi\left(A_{t}, K_{\mathrm{t}}\right)$ has been computed, $\varphi^{*}\left(K_{t} / A_{t}\right)=\varphi\left(A_{t}, K_{\mathrm{t}}\right) / A_{t}$. Note that if the two costs of capital are equal $\left(c^{A}=c^{K}\right)$ during all time periods, $\varphi^{*}\left(K_{t} / A_{t}\right)$ simply becomes $1+K_{t} / A_{t}$. Even if the costs of capital are not identical, if they change similarly over time, $\varphi^{*}\left(K_{t} / A_{t}\right)$ will be highly collinear with $K / A$ itself. Thus if the relative user costs do not vary much, separate identification of the coefficients of $K / A$ (the relative value of current R\&D assets) and $\varphi^{*}\left(K_{t} / A_{t}\right)$ (the relative value of the expected rents from these assets) may be impossible.

Because the panel is very unbalanced, there is an extra complication in the capital aggregate computation due to the need to normalize the price series in a base year. My solution to this problem is to first construct aggregate price and quantity series for capital using all the firms in the sample and normalizing price to unity in the first period. I then use equation (23) for each firm, with the initial year value of the price index normalized to the aggregate value. Figure 5 shows the resulting indices (aggregate and averaged over firms) normalized to one for ordinary capital in the first year, for the sample of large US manufacturing firms used later in the paper. The index of aggregate capital (adjusted for the relative costs of capital) is roughly constant at around 1.4 (implying that R\&D capital is 40 per cent of the level of ordinary capital), whereas the index of capital for the average firm falls slightly during the 1990s as smaller firms enter the sample. In addition, the dispersion rises, from an interquartile range of about 0.2 to 0.8 , as more R\&D-intensive firms enter the sample.

As was noted earlier, the coefficients of $\varphi$ and $K / A$ in the regression equations (21) or (22) will only be separately identified when $\varphi$ is sufficiently nonlinear in $K / A$, that is, when the costs of the two capitals follow different paths over time (or when they vary across firms, which is somewhat harder to justify, although variations in the supply of trained personnel in various scientific fields might imply some variation in the cost of $\mathrm{R} \& \mathrm{D}$ ). To assess this possibility, $\varphi$ was regressed on $K / A$, allowing both the slope and the intercept to vary by year of the data. Although $K / A$ explains most of the variance in $\varphi$, about 7 per cent remains to be explained, which is enough to identify the two coefficients separately, but not enough to prevent very unstable behavior due to the imprecision of the estimates. ${ }^{17}$

\footnotetext{
${ }^{17}$ Adding to the difficulty is the fact that both are presumably measured with considerable error, and error that is correlated. Hall (2004) shows that using two proxy variables for the same underlying concept in a regression, where one is better measured than the other but their measurement errors are correlated will lead to biased estimates where the two variables actually have opposite signs in the regression.
} 
Two possible solutions exist to this problem. The first is to impose unity on the coefficient of $K / A$ as implied by the HI model, and then simply estimate that coefficient of the term corresponding to the supranormal rents from the capitals. The second takes a slightly different approach and is in the spirit of Griliches' original article: because the capital aggregator term is supposed to capture the supranormal rents to be earned in the future from the firm's current portfolio of assets, it might be possible to proxy for that term using the deviation of the firm's R\&D spending in the current year from what was forecast by past $R \& D$. That is, if the firm is earning an above normal return from its current stock of $R \& D$, it might be expected to increase its $\mathrm{R} \& \mathrm{D}$ investment in order to drive the return down. These two possibilities are explored below.

Table B1 shows the result of estimating several versions of equation (11) for each of the six 5-year panels, with industry and time dummies included. The first column includes only a term for the nominal $K / A$ ratio $\left.\left[p^{R} K / p^{I} A\right)\right]$ along with the dummies. As is familiar from previous work, the coefficients of this ratio are less than unity in all periods, suggesting that the measured ratio is biased upwards, that is, that $K$ actually depreciates more quickly than implied by the 15 per cent rate that was used to construct it.

\section{[Table B1 about here]}

The second column adds the capital aggregator $\varphi^{*}(K / A)$ to the equation, with an interesting effect: the coefficient of K/A is now closer to the theoretical value of unity in all periods, whereas the coefficient of $\varphi *$ is substantially negative everywhere. The third column imposes the restriction that the coefficient is unity, with little change in the estimates. The interpretation of the negative coefficient on $\varphi^{*}$ is that if the $\mathrm{R} \& \mathrm{D}$ stock has been computed correctly (so that its coefficient should be one in equilibrium), then the more $R \& D$ intensive the capital aggregate is, the lower is the market value of the firm, controlling for the year, industry, and the level of tangible and intangible assets. In short, the expected supranormal rents for a firm that is more R\&D-intensive than the typical firm in its industry are negative, with the possible exception of the last period, where the coefficient of $\varphi^{*}$ is near zero. However, this conclusion relies heavily on having used the "correct" depreciation rate for R\&D when constructing the R\&D capital stock. If the stock is overestimated, the negative coefficient on $\varphi^{*}$ can be due to mismeasurement in two highly correlated variables, which often leads to coefficients of opposite sign (Hall 2004).

The fourth and final column includes two measures of $K / A$ separately: the first is the news in $R \& D$, computed as the difference between the actual $R / A$ ratio and that predicted from past $\mathrm{K}$, time, and year 
dummies. The second is simply the lagged value of $K / A \cdot{ }^{18}$ Except in the final period, lagged $K / A$ enters with a coefficient that is somewhat higher than that of contemporaneous $K / \mathrm{A}$ in the previous estimates. In spite of this, the "news in R\&D" term is highly significant and the coefficient is about 8 times that for the stock of R\&D. That is, an additional dollar of $R \& D$ that is not simply a continuation of the past spending history is valued 8 times as much as a dollar that has already been sunk. So although high R\&D intensity relative to the industry intensity may be negative for value, increasing R\&D is clearly a positive signal. ${ }^{19}$

${ }^{18}$ Note that the variables are nearly but not exactly orthogonal. Their correlation is approximately 0.15 .

${ }^{19}$ Recall that the market value is measured at the end of the year and R\&D is flow during the year, so that both may be driven by changes in the firm's profit expectations. 
Figure B1

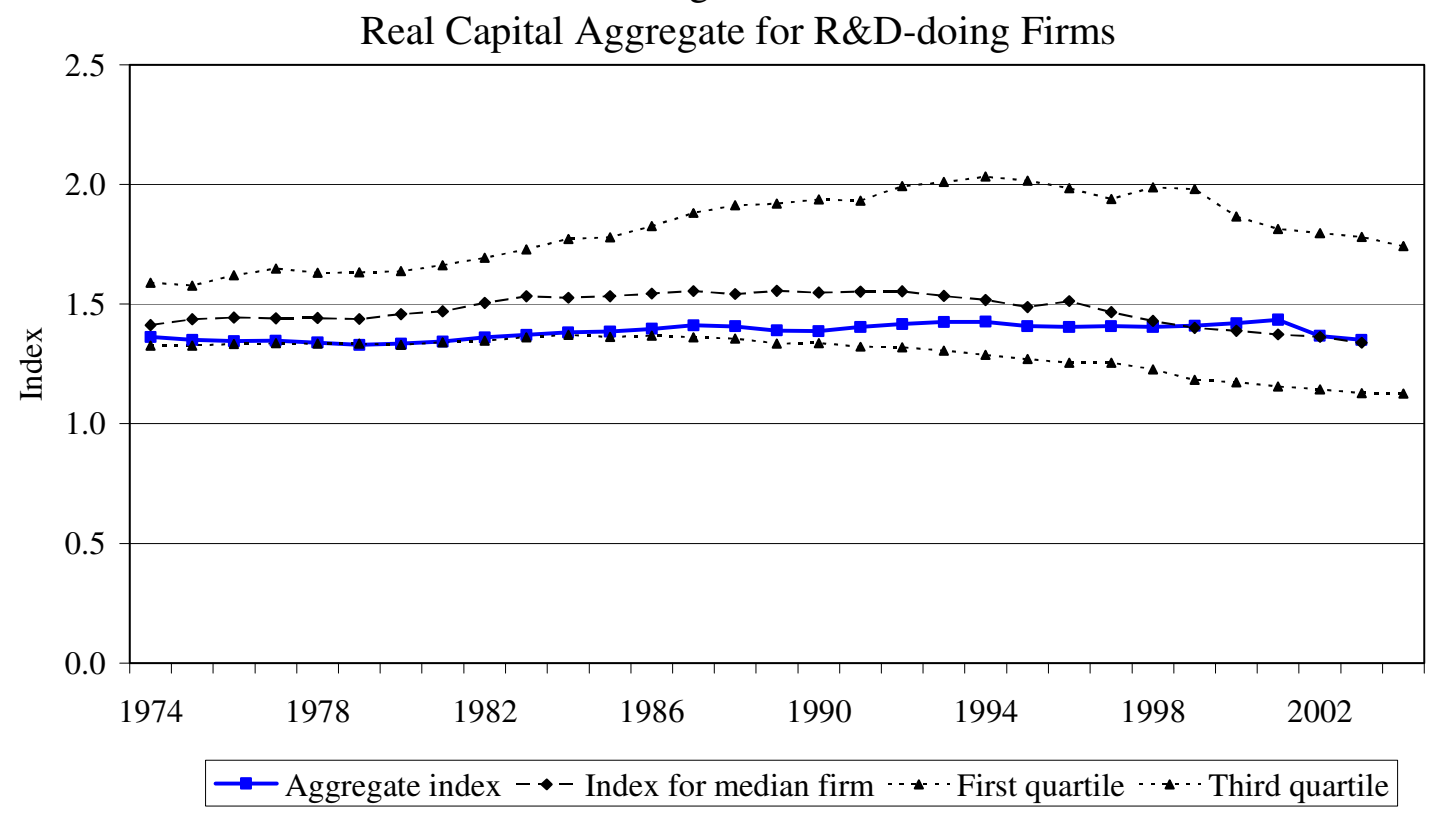

Figure B2

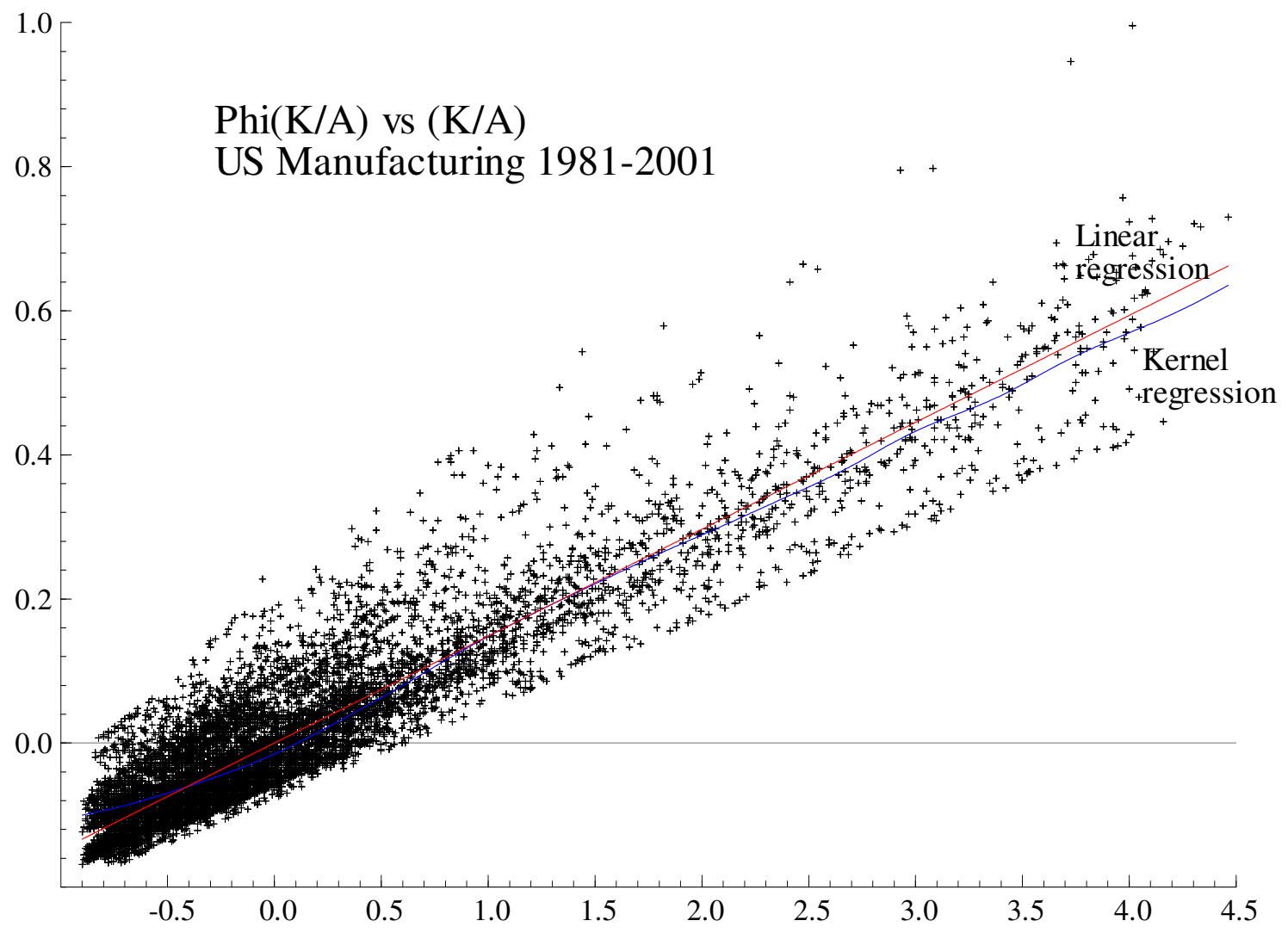


Table B1

The Market Value-R\&D Relation: Exploring the Functional Form US Manufacturing Firms

\begin{tabular}{|c|c|c|c|c|c|c|c|c|}
\hline \multirow[b]{3}{*}{$\varphi^{*}(\mathrm{~K} / \mathrm{A})$} & \multicolumn{2}{|c|}{$(0)$} & \multicolumn{2}{|c|}{$(1)$} & \multicolumn{2}{|c|}{ (2) } & \multicolumn{2}{|c|}{ (3) } \\
\hline & \multicolumn{8}{|c|}{ 1974-1978 3045 observations } \\
\hline & & & -0.41 & $(0.03)$ & -0.38 & $(0.03)$ & & \\
\hline $\mathrm{R} / \mathrm{A}$ surprise* & & & & & & & 4.71 & $(0.03)$ \\
\hline $\mathrm{K} / \mathrm{A} * *$ & 0.53 & $(0.03)$ & 0.72 & $(0.03)$ & \multicolumn{2}{|c|}{1.00} & 0.61 & $(0.03)$ \\
\hline R-squared & \multicolumn{2}{|c|}{0.188} & \multicolumn{2}{|c|}{0.198} & & & \multicolumn{2}{|c|}{0.226} \\
\hline \multirow[t]{2}{*}{ Standard error } & \multicolumn{2}{|c|}{0.441} & & & \multicolumn{2}{|c|}{0.442} & \multicolumn{2}{|c|}{0.430} \\
\hline & \multicolumn{8}{|c|}{ 1979-1983 2990 observations } \\
\hline$\varphi^{*}(\mathrm{~K} / \mathrm{A})$ & & & -0.43 & $(0.02)$ & -0.45 & $(0.02)$ & & \\
\hline R/A surprise* & & & & & & & 6.76 & $(0.02)$ \\
\hline $\mathrm{K} / \mathrm{A} * *$ & 0.60 & $(0.02)$ & 0.79 & $(0.02)$ & & & 0.80 & $(0.02)$ \\
\hline R-squared & & & & & & & & \\
\hline \multirow[t]{2}{*}{ Standard error } & & & & & & & & \\
\hline & \multicolumn{8}{|c|}{ 1984-1988 2535 observations } \\
\hline$\varphi *(\mathrm{~K} / \mathrm{A})$ & & & -0.34 & $(0.03)$ & -0.30 & $(0.03)$ & & \\
\hline $\mathrm{R} / \mathrm{A}$ surprise* & & & & & & & 3.24 & $(0.03)$ \\
\hline $\mathrm{K} / \mathrm{A}^{* *}$ & 0.39 & $(0.03)$ & 0.62 & $(0.03)$ & & & 0.47 & $(0.03)$ \\
\hline R-squared & & & & & & & & \\
\hline \multirow[t]{2}{*}{ Standard error } & & & & & & & & \\
\hline & \multicolumn{8}{|c|}{ 1989-1993 2915 observations } \\
\hline$\varphi^{*}(\mathrm{~K} / \mathrm{A})$ & & & -0.40 & $(0.03)$ & -0.39 & $(0.03)$ & & \\
\hline $\mathrm{R} / \mathrm{A}$ surprise* & & & & & & & 3.43 & $(0.03)$ \\
\hline $\mathrm{K} / \mathrm{A}^{* *}$ & 0.38 & $(0.03)$ & 0.64 & $(0.03)$ & & & 0.50 & $(0.03)$ \\
\hline R-squared & & & & & & & & \\
\hline \multirow[t]{2}{*}{ Standard error } & & & & & & & & \\
\hline & \multicolumn{8}{|c|}{ 1994-1998 2735 observations } \\
\hline$\varphi *(\mathrm{~K} / \mathrm{A})$ & & & -0.38 & $(0.03)$ & -0.38 & $(0.03)$ & & \\
\hline $\mathrm{R} / \mathrm{A}$ surprise* & & & & & & & 5.15 & $(0.03)$ \\
\hline $\mathrm{K} / \mathrm{A}^{* *}$ & 0.55 & $(0.03)$ & 0.71 & $(0.03)$ & & & 0.62 & $(0.03)$ \\
\hline R-squared & & & & & & & & \\
\hline \multirow[t]{2}{*}{ Standard error } & & & & & & & & \\
\hline & \multicolumn{8}{|c|}{ 1999-2003 2530 observations } \\
\hline$\varphi^{*}(\mathrm{~K} / \mathrm{A})$ & & & -0.16 & $(0.04)$ & -0.10 & $(0.04)$ & & \\
\hline $\mathrm{R} / \mathrm{A}$ surprise* & & & & & & & 6.93 & $(0.04)$ \\
\hline $\mathrm{K} / \mathrm{A}^{* *}$ & 0.79 & $(0.04)$ & 0.80 & $(0.04)$ & & & 0.94 & $(0.04)$ \\
\hline R-squared & & & & & & & & \\
\hline Standard error & & & & & & & & \\
\hline
\end{tabular}

Nonlinear least squares estimates with dependent variable log Q, robust standard errors.

14 sector dummies and 4 year dummies are included in the equation.

*This variable is the actual R/A less the fitted value from a regression of log R/A on log K/A lagged plus time and industry dummies.

**In the last column this variable is lagged one period. 


\section{Appendix C: The rate of return formulation}

Earlier researchers (Mansfield 1965; Terleckyj 1974; Griliches 1980) had used an alternative formulation to estimate the returns to $R \& D$, one that was derived from the first differenced version of equation (2) under the assumption that the depreciation of $R \& D$ is approximately zero:

$$
\begin{gathered}
\Delta y_{i t}=\Delta \lambda_{t}+\alpha \Delta l_{i t}+\beta \Delta c_{i t}+\gamma \Delta k_{i t}+\Delta u_{i t} \\
\Delta k_{i t}=\frac{R_{i t}-\delta K_{i, t-1}}{K_{i, t-1}} \\
\Rightarrow \gamma \Delta k_{i t}=\left(\gamma \frac{Y_{i t}}{K_{i, t-1}}\right) \frac{R_{i t}}{Y_{i t}}=\rho \frac{R_{i t}}{Y_{i t}}
\end{gathered}
$$

where $\rho$ is the gross rate of return to R\&D capital, and the appropriate independent variable is the firm's $R \& D$ intensity ( $R \& D$ to sales ratio). ${ }^{20}$ This version of the model had the advantage that the gross rate of return, rather than the production function coefficient, was assumed to be equalized across firms. Of course, it would be preferable for the net rate of return to be equalized, but that would take us back to the problem of measuring the depreciation of $R \& D$.

Note that in order to obtain equation (24), R\&D depreciation was assumed to be zero, which is clearly counterfactual. ${ }^{21}$ The true net investment rate may be substantially lower than that measured by the gross $R \& D$ spending-sales ratio. To see the consequences of this assumption, use equation (4) to construct an approximation to net $\mathrm{R} \& \mathrm{D}$ investment:

$$
\begin{aligned}
& \Delta k_{i t}=\frac{R_{i t}-\delta K_{i, t-1}}{K_{i, t-1}} \cong \frac{R_{i t}-\delta R_{i, t-1} /\left(\delta_{i}+g_{i}\right)}{K_{i, t-1}}=\frac{R_{i t}}{K_{i, t-1}}\left[1-\frac{\delta_{i}}{\left(1+g_{i}\right)\left(\delta_{i}+g_{i}\right)}\right] \\
& \Rightarrow \hat{\rho} \cong\left[1-\frac{\delta_{i}}{\left(1+g_{i}\right)\left(\delta_{i}+g_{i}\right)}\right] \rho \simeq\left[\frac{g_{i}}{\delta_{i}+g_{i}}\right] \rho
\end{aligned}
$$

\footnotetext{
${ }^{20}$ Equation (5) is written using real rather than nominal variables whereas $R \& D$ intensity is usually measured using nominal variables. This will make little difference in the end to the measured rate of return as long as time dummies are included and prices do not change too quickly over time.

${ }^{21}$ This formulation was initially applied to more aggregate date, where the assumption of zero depreciation rate is more appropriate.
} 
This equation shows that the estimated gross rate of return in the R\&D intensity formulation underestimates the true rate of return by the ratio of $R \& D$ growth to the sum of $R \& D$ growth plus depreciation. In the sample used in this paper, the median past growth of real R\&D ranges from about 4 per cent per annum in the earlier period to 10 per cent in the latter. If the depreciation rate is 15 per cent, this implies that the true gross rate of return will be 2.5 to 5 times the estimated value, a point which seems to have gone unnoticed in the literature. 